\title{
Rodent models of post-traumatic stress disorder: behavioral assessment
}

\author{
Alexander Verbitsky (1)', David Dopfel (1) ${ }^{2}$ and Nanyin Zhang $\mathbb{1}^{2,3}$
}

\begin{abstract}
Although the etiology and expression of psychiatric disorders are complex, mammals show biologically preserved behavioral and neurobiological responses to valent stimuli which underlie the use of rodent models of post-traumatic stress disorder (PTSD). PTSD is a complex phenotype that is difficult to model in rodents because it is diagnosed by patient interview and influenced by both environmental and genetic factors. However, given that PTSD results from traumatic experiences, rodent models can simulate stress induction and disorder development. By manipulating stress type, intensity, duration, and frequency, preclinical models reflect core PTSD phenotypes, measured through various behavioral assays. Paradigms precipitate the disorder by applying physical, social, and psychological stressors individually or in combination. This review discusses the methods used to trigger and evaluate PTSD-like phenotypes. It highlights studies employing each stress model and evaluates their translational efficacies against DSM-5, validity criteria, and criteria proposed by Yehuda and Antelman's commentary in 1993. This is intended to aid in paradigm selection by informing readers about rodent models, their benefits to the clinical community, challenges associated with the translational models, and opportunities for future work. To inform PTSD model validity and relevance to human psychopathology, we propose that models incorporate behavioral test batteries, individual differences, sex differences, strain and stock differences, early life stress effects, biomarkers, stringent success criteria for drug development, Research Domain Criteria, technological advances, and cross-species comparisons. We conclude that, despite the challenges, animal studies will be pivotal to advances in understanding PTSD and the neurobiology of stress.
\end{abstract}

\section{Introduction}

Post-traumatic stress disorder (PTSD) is an incapacitating chronic disorder. With a $3.9 \%$ lifetime prevalence rate worldwide and a $6.4-7.8 \%$ rate in the USA, PTSD's health burden is substantial ${ }^{1-5}$. Based on the World Mental Health Surveys, $69.7 \%$ worldwide $(82.7 \%$ in the USA) reported exposure to a traumatic experience. While trauma exposure is a required criterion for PTSD diagnosis, only $5.6 \%$ worldwide ( $8.3 \%$ in the USA) of those who experienced trauma developed the disorder ${ }^{1}$. This is due to numerous factors, including trauma type, variation

Correspondence: Nanyin Zhang (nuz2@psu.edu)

${ }^{1}$ Department of Engineering Science and Mechanics, The Pennsylvania State University, University Park, PA 16802, USA

${ }^{2}$ Department of Biomedical Engineering, The Pennsylvania State University, University Park, PA 16802, USA

Full list of author information is available at the end of the article in trauma response, social support, and endogenous factors of individuals. For adults, adolescents, and children older than six years, eight diagnostic criteria, defined in the 5th edition of the Diagnostic and Statistical Manual of Mental Disorders (DSM-5), specify measures concerning the victim's perception of trauma and symptoms. For children six years and younger, Criteria C and D (described below) are combined, making for seven diagnostic criteria ${ }^{6}$.

Criterion A: Exposure to actual or threatened death, serious injury, or sexual violence; one or more ways (e.g., direct experience, witnessing others, learning of close family member's or friend's trauma, and repeated or extreme exposure to aversive details).

Criterion B: Intrusion; one or more symptoms (e.g., nightmares, flashbacks, intrusive thoughts, and physiological reactions to trauma reminders). 
Criterion C: Avoidance of trauma related stimuli; one or more symptoms (e.g., avoiding thoughts, people, places, conversations, activities, objects, or situations that arouse distressing memories).

Criterion D: Negative alterations in cognition and mood; two or more symptoms (e.g., dissociative amnesia, emotional blunting, cognitive distortion, social withdrawal, and anhedonia).

Criterion E: Alterations in arousal and reactivity; two or more symptoms (e.g., irritable and aggressive behavior, reckless or self-destructive behavior, hypervigilance, exaggerated startle response, concentration problems, and sleep disturbance).

Criterion F: Symptom duration for over one month (Criteria B, C, D, and E).

Criterion G: Functional impairment (e.g., social or occupational).

Criterion H: Disturbance not attributable to substance effects or medical conditions.

Specify whether/if: With dissociative symptoms (depersonalization, derealization) or with delayed expression (full diagnostic criteria not met for at least six months).

Pretraumatic, peritraumatic, and posttraumatic risk and prognostic factors affect the prevalence of the above symptoms.

\section{Pretraumatic factors.}

Temperamental: Childhood emotional problems by age 6 and prior mental disorders.

Environmental: Lower socioeconomic status, lower education, prior trauma, childhood adversity, cultural characteristics, lower intelligence, minority racial/ethnic status, family psychiatric history, and social support (protective).

Genetic and physiological: Female, younger age at time of trauma, and certain genotypes.

\section{Peritraumatic factors.}

Environmental: Trauma severity, perceived life threat, personal injury, interpersonal violence, dissociation, and being a perpetrator, witnessing atrocities, or killing the enemy (for military personnel).

\section{Posttraumatic factors}

Temperamental: Negative appraisals, inappropriate coping strategies, and development of acute stress disorder.

Environmental: Subsequent exposure to repeated upsetting reminders, subsequent adverse life events, financial or trauma-related losses, and social support (protective).

Like for many mental disorders, animal models play a key role in deciphering the neuropathophysiology of PTSD. Although observing humans to learn about mental disorders is effective, the major obstacles to human investigations are that PTSD is variable and seldom studied throughout disorder development. Therefore, human research focuses on populations already exposed to different uncontrolled traumatic events. Animal models overcome these barriers through the ability to longitudinally monitor PTSD development pre-trauma through posttrauma with controlled stressors. In particular, rodent models are critical to understanding PTSD induction, facilitating target identification for therapies, and testing drugs for human treatment. However, these models are simplified representations of a complex condition. PTSD is challenging to model in rodents because susceptibility, an individual's likelihood to develop long term symptomology, is influenced by the above factors. While there is no gold standard paradigm, animal models are expected to capture PTSD symptomatology (face validity), etiology (construct validity), and treatment response (predictive validity) ${ }^{7}$. As such, Yehuda and Antelman defined five criteria for the face validity of translational models: (1) the stressor induces PTSD biological and behavioral responses, (2) responses are intensity-dependent, (3) biological alterations persist or progress over time, (4) biobehavioral alterations are bidirectional, and (5) responses have inter-individual variability caused from experience, genetics, or both ${ }^{8}$. PTSD rodent models have been previously reviewed ${ }^{9-15}$. This review offers a comprehensive assessment of stress model variants against multiple criteria with a focus on behavioral assays used for model validation. Although a comprehensive rodent PTSD model is challenging to develop, the demand for more effective PTSD treatment and prevention strategies drives further research. Therefore, various stress paradigms that replicate specific disorder aspects are utilized to understand the pathophysiology of PTSD. Through a survey of recent literature, this review discusses rodent PTSD models that utilize acute stress, evaluating their translational efficacies, advantages, and challenges. The review concludes by highlighting opportunities for future work in studying the neurobiology of PTSD.

\section{Rodent models of PTSD}

Although the etiology and manifestation of psychiatric disorders are complex, mammals show biologically preserved behavioral and neurobiological responses to valent stimuli which underlie the use of rodent models of PTSD. The translational benefit of designing stress studies in rodents is supported by extensive comparative neuroanatomical studies ${ }^{16-18}$. Accordingly, the rodent models discussed reflect core PTSD phenotypes and vary by differences in stress type, intensity, duration, and frequency. Paradigms model the disorder by applying physical, social, and psychological stressors individually or in combination (Table 1). This review focuses on acute stressors and does not extensively address sub-chronic and chronic models because acute stressors are less likely to drive the symptom co-morbidity seen in other models. Behavioral tests 


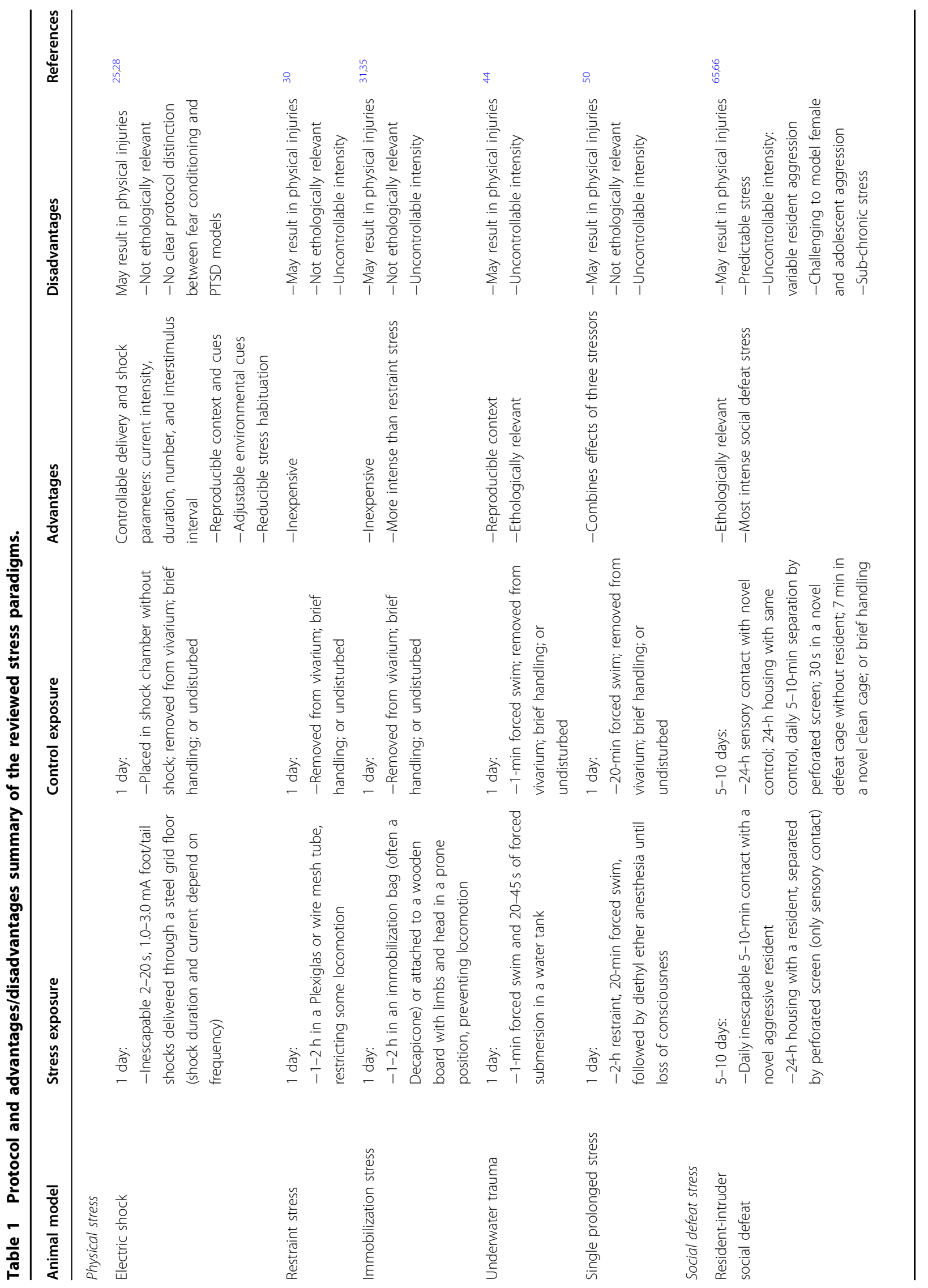




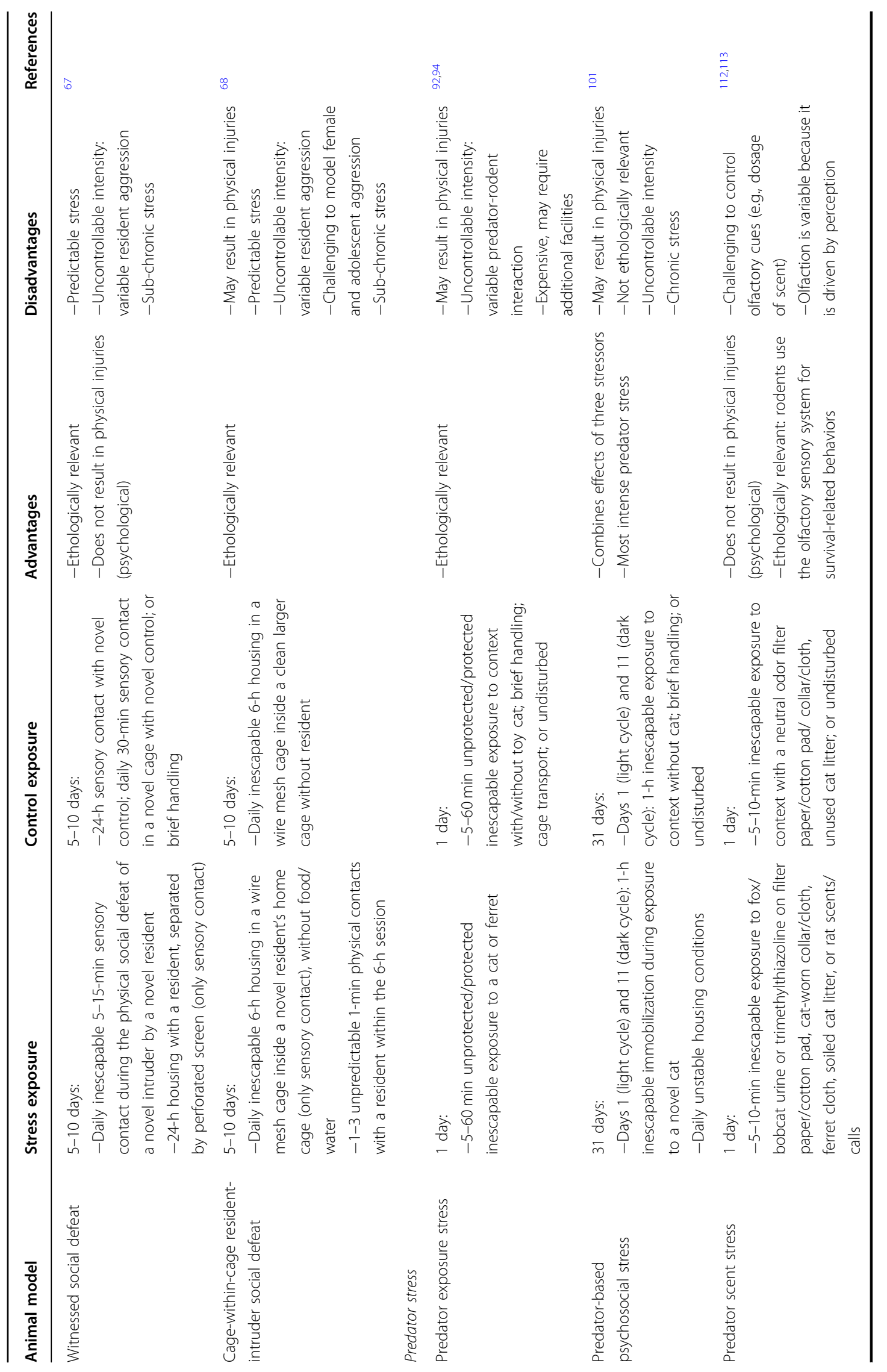


mentioned in this survey are discussed further in Table 2 . In literature, behavioral tests are frequently referred to as models. This can be misleading, and scientists should recognize their distinction, because tests elicit acute responses for measurement while models elicit pathology ${ }^{19}$.

\section{Physical stressors}

Physical stressors used to develop PTSD models include electric shock, underwater trauma, restraint/immobilization stress, and single prolonged stress. These stressors are advantageous for their procedural simplicity, clear symptom impact, and ease of scaling. Although widely utilized, physical stressors have not reproducibly differentiated individual variability or sex differences because most subjects display behavioral consequences. Physical stressors can also elicit injuries, pain, and/or inflammatory responses that can confound behavioral test results, including measures of motivation and movement ${ }^{20}$.

\section{Electric shock}

Electric shock is employed in animal models of anxiety, depression $^{21}$, and PTSD. Inescapable and unpredictable electric shock can be administered through the animal's tail or foot via a steel grid floor in a shock chamber. These studies combined high-intensity currents (1.0-3.0 mA) with long durations $(2-20$ s) to induce lasting symptoms. Currents and durations were typically larger than those applied in fear conditioning (0.5-1.5 mA, 0.5-2 s) aiming to investigate short-term fear learning. Currently, learning and trauma protocols are not clearly differentiated as there is no clear evidence for separating "nontraumatic" shocks that are within a rodent's coping capacity from "traumatic" shocks that are beyond its coping capacity ${ }^{22}$. However, this stressor is more frequently used to study learning and memory, its initial application, rather than to model PTSD. Electric shock may be combined with contextual and/or cued trauma reminders (associative fear) through re-exposure to shock chambers and conditioned stimuli, and with neutral stimuli in a novel environment (non-associative fear). In stress-enhanced fear learning, pre-exposure to repeated intense footshocks in context A increased rodent fear response in context B when only a single shock, a less intense stressor, was administered $^{23}$. This non-associative sensitization effect elevated freezing in context B for three months, even after context A extinction training, reflecting resistance to exposure therapy (extinction) ${ }^{24}$. Upon similar situational reminders, rodents exhibited behavioral responses comparable to human PTSD intrusion symptoms, such as crouching against the chamber wall, as well as increased freezing, respiratory rate, and fecal boli ${ }^{25-27}$. Since reexposure to stressor-related environments/cues is the clinical analog of exposure therapies, the electric shock model can be studied to advance cue-based out-of- context (reminders in office) and in-context (virtual reality) therapies ${ }^{14}$. Advantages of electric shock as a PTSD model are its controllable delivery and shock parameters (current intensity, duration, number, and interstimulus interval), reproducible context and cues, adjustable environmental cues, and reducible stress habituation ${ }^{28}$. For review of electric shock, see Aliczki and Bali \& $\operatorname{Jaggi}^{22,29}$.

\section{Restraint/immobilization stress}

Restraint and immobilization stresses include confining rodents in enclosed chambers to limit movement for an extended period of time. Restraint stress is generally conducted by placing animals in Plexiglas or wire mesh tubes $^{30}$. Immobilization stress is achieved by either placing animals into rodent immobilization bags (often Decapicones) ${ }^{31-33}$ or attaching the animal's limbs and head in a prone position to wooden boards ${ }^{34,35}$. Currently, restraint and immobilization protocols are not clearly differentiated and the two terms are often used interchangeably ${ }^{36}$. While restraint and immobilization are similar in that they are stressors driven by the limitation of motion, it is important to make the distinction between the two as restraint does not prevent, but only restricts, movement of the rodent's limbs, body, and head. Accordingly, immobilization elicits stronger responses than restraint ${ }^{37}$. There are no comparative studies favoring any one acute stress protocol. Furthermore, only two studies comparing the sex-dependent effects of immobilization stress have been reported. One study found that the attribution of incentive salience toward food reward location (goal-tracking) was increased in Long-Evans males exposed to acute immobilization stress, whereas a bias toward food rewardassociated cues (sign-tracking) was increased in females. This suggests sex-differences in the failure to appropriately assign motivational value as related to amotivation/anergia and anhedonia ${ }^{38}$. Another study, in agreement with one subgroup of human endocrine responses ${ }^{39,40}$, reported that immobilization stress evokes long-term hypothalamic-pituitary-adrenal (HPA) axis desensitization following re-exposure to the same (homotypic) stressor and sensitization to novel (heterotypic) stressors ${ }^{35}$. This effect was greater in female Sprague-Dawley rats ${ }^{41}$. Studies also noted delayed expression (10 days post-stress) of avoidance behavior and changes in dendritic spine density in the basolateral amygdala, a stress responsive brain region ${ }^{31}$. For review of restraint and immobilization stress, see Buynitsky ${ }^{42}$.

\section{Underwater trauma}

Underwater trauma, or submersion stress, involves $1 \mathrm{~min}$ of forced swim followed by $30 \mathrm{~s}$ of forced submersion in a water tank. Exposed rats demonstrated 
Table 2 Rodent behavioral tests outlined by DSM-5 criteria for PTSD.

\begin{tabular}{|c|c|}
\hline Behavioral test & Description \\
\hline Criterion B & Intrusion \\
\hline $\begin{array}{l}\text { Contextual and cued } \\
\text { trauma reminders }\end{array}$ & Physiological and behavioral reactions to exposure arena \\
\hline Criterion C & Avoidance \\
\hline Elevated plus-maze & $\begin{array}{l}\text { Elevated platform arranged in a }+ \text { with four perpendicular } \\
\text { opposite arms: two open, two closed }\end{array}$ \\
\hline Elevated T-maze & $\begin{array}{l}\text { Elevated platform arranged in a } T \text { with three perpendicular } \\
\text { opposite arms: one open, two closed }\end{array}$ \\
\hline Elevated zero-maze & $\begin{array}{l}\text { Elevated circular platform with two opposite open and closed } \\
\text { quadrants }\end{array}$ \\
\hline Light-dark box & $\begin{array}{l}\text { Two-compartment box: one white and illuminated, the other } \\
\text { black and dark. A small opening connects the compartments }\end{array}$ \\
\hline Open field & $\begin{array}{l}\text { Square, rectangular, or circular enclosure that is bare or covered } \\
\text { with a thin layer of bedding }\end{array}$ \\
\hline $\begin{array}{l}\text { Novelty suppressed } \\
\text { feeding }\end{array}$ & $\begin{array}{l}\text { Open field with novel food (e.g., sugar puffs, fruit loops) in an } \\
\text { illuminated central area }\end{array}$ \\
\hline Hole board & $\begin{array}{l}\text { Elevated and open-topped square box with evenly spaced holes } \\
\text { in the floor }\end{array}$ \\
\hline Modified hole board & $\begin{array}{l}\text { Open field with a hole board in the middle. The hole board } \\
\text { consists of staggered holes covered by removable lids }\end{array}$ \\
\hline $\begin{array}{l}\text { Conditioned taste } \\
\text { aversion }\end{array}$ & $\begin{array}{l}\text { Conditioned stimulus (e.g., novel taste of saccharin) is paired } \\
\text { with an unconditioned stimulus (e.g., lithium chloride injection } \\
\text { that results in nausea, stress and re-stress). Recipients avoid the } \\
\text { new taste when it is subsequently presented }\end{array}$ \\
\hline $\begin{array}{l}\text { Conditioned object } \\
\text { avoidance }\end{array}$ & $\begin{array}{l}\text { Conditioned stimulus (e.g., plastic prism) is paired with an } \\
\text { unconditioned stimulus (e.g., electric footshock). In separate } \\
\text { tests, a plastic prism or cube (novel object) is placed into the } \\
\text { home cage }\end{array}$ \\
\hline $\begin{array}{l}\text { Conditioned odor } \\
\text { avoidance }\end{array}$ & $\begin{array}{l}\text { Conditioned stimulus (e.g., odor of ethanol) is paired with an } \\
\text { unconditioned stimulus (e.g., electric footshock). Three- } \\
\text { compartment box interconnected by guillotine doors. Center } \\
\text { (nest) compartment: filter paper-lined Petri dish with home-cage } \\
\text { bedding, cleaned with soapy water. Left/right compartments, } \\
\text { counterbalanced: Petri dish with ethanol or acetate (novel } \\
\text { neutral odor) solutions, cleaned with respective solutions. } \\
\text { Habituation phase: rodent in nest compartment. Test phase: free } \\
\text { exploration }\end{array}$ \\
\hline
\end{tabular}

Conditioned odor active Conditioned stimulus (e.g., odor of acetic acid) is paired with an avoidance unconditioned stimulus (e.g., electric footshock). Twocompartment box: start compartment cleaned with acetic acid solution, the other with ethanol solution (novel neutral odor)

Territory discrimination Two boxes linked to a starting box with litter covering the floor. The tested animal and a novel conspecific stay in separate compartments (personal and unknown) for $24 \mathrm{~h}$ before testing Measures

Heart rate, body temperature, systolic blood pressure, diastolic 25,224 blood pressure, plasma corticosterone, time freezing, total locomotor activity

$\%$ time spent in open arms, \% entries made into open arms

Latency to leave enclosed arm, latency to enter enclosed arm

$\%$ time spent in open arms, frequency of head dips over edge of 227 platform, frequency of stretched-attend postures

Time spent in light, number of light entries, \% distance in light, 228,229 number of rears, latency to enter light, number of transitions

Time spent in central squares, latency to enter central squares 230

Latency to eat 23

Latency to head dip, number of head dips, number of rears, time ${ }^{92}$ active, time spent in center

Latency to board entry, number of board entries, \% time spent 232 on board

Saccharin/cyclamate intake

Time spent with familiar/novel object, time spent burying familiar/novel object, total locomotor activity and/or sniffing floor/walls

Latency to first exit from nest compartment, time spent in nest/ 235 ethanol/acetate compartment

$\%$ time spent in acetic acid compartment, number of rears toward the acetic acid compartment

Time spent in personal/unknown compartment, number of entries to personal/unknown compartment

Criterion D

Morris water maze Negative alterations in cognition and mood

Black circular tank filled with water in a room with visual cues on walls. The tank is conceptually divided into four quadrants and four start locations (N, S, E, W). Training sessions: animals locate or are guided to a small submerged platform (target quadrant). Probe trial: platform is removed to assess memory of its location

Radial arm water maze Black circular tank filled with water. The tank contains 4-12 Vshaped inserts that produce swim arms radiating from an open central area. Training trials: animals locate or are guided to a small submerged platform at the end of one arm (goal arm). Test trial: platform is removed to assess memory of its location

T-maze continuous alteration task

Elevated or enclosed platform arranged in a T with three perpendicular opposite arms: two identical goal arms and one longer start arm. Arms are separated by guillotine doors and a central partition extends into the start arm. Testing consists of one forced trial and several free-choice trials

Novel object recognition Open field with two objects at opposite and symmetrical

Y-maze spontaneous alternation test

Y-maze recognition memory test corners. Habituation phase: no objects. Familiarization phase: two identical objects. Test phase: one familiar, one novel object Platform ar

Time spent with familiar/novel object, number of familiar/novel ${ }^{241}$ object entries, discrimination index, index of global habituation, recognition index, preference index

$\%$ alternation rate

Platform arranged in a $Y$ with three identical arms at $120^{\circ}$ from Time spent in familiar/novel arms, discrimination index each other. Acquisition phase: access to two arms, one arm closed (novel arm). Retrieval phase: access to all arms 
Table 2 continued

\begin{tabular}{|c|c|c|c|}
\hline Behavioral test & Description & Measures & References \\
\hline Barnes maze & $\begin{array}{l}\text { Circular table with equally spaced holes around its } \\
\text { circumference. The table's surface is illuminated and a box is } \\
\text { under the target hole. Acquisition trials: animals locate or are } \\
\text { guided into the target hole. Reversal phase: target hole is moved } \\
180^{\circ} \text { across the maze. Probe trial: target cage is removed to } \\
\text { assess memory of its location }\end{array}$ & $\begin{array}{l}\text { Latency to enter the target hole, distance traveled to the target } \\
\text { hole, number of errors, number of entries into the former target } \\
\text { hole during reversal/probe }\end{array}$ & 244,245 \\
\hline $\begin{array}{l}\text { Cued and contextual fear } \\
\text { conditioning / Fear } \\
\text { extinction }\end{array}$ & $\begin{array}{l}\text { Operant chamber in a ventilated, sound-attenuated cubicle with } \\
\text { a shock grid floor, speaker, and video camera. An unconditioned } \\
\text { stimulus footshock is paired with a conditioned stimulus tone or } \\
\text { context. Fear conditioning involves longer intertrial intervals and } \\
\text { fewer stimuli than fear extinction training/testing }\end{array}$ & Time freezing & 246,247 \\
\hline $\begin{array}{l}\text { Differential contextual } \\
\text { odor conditioning }\end{array}$ & $\begin{array}{l}\text { Cue (cinnamon odor) signals reward or punishment depending } \\
\text { on the context. Appetitive conditioning (arena 1): cue }+ \text { reward } \\
\text { (sweetened water). Aversive conditioning (arena 2): cue }+ \\
\text { conditioned cue (tone) + aversive unconditioned stimulus } \\
\text { (electric shock). Testing (arena 3): cue }\end{array}$ & $\%$ time freezing & 248 \\
\hline $\begin{array}{l}\text { Step-through inhibitory } \\
\text { (passive) avoidance }\end{array}$ & $\begin{array}{l}\text { Two-compartment box: one white and illuminated (safe), the } \\
\text { other black and dark (unsafe). A sliding door connects the } \\
\text { compartments. Training phase: door closes upon entrance to the } \\
\text { dark compartment and an unconditioned stimulus footshock is } \\
\text { delivered. Testing phase: no shock }\end{array}$ & $\begin{array}{l}\text { Latency to enter the dark compartment, time spent in dark } \\
\text { compartment }\end{array}$ & 249 \\
\hline $\begin{array}{l}\text { Response bias } \\
\text { probabilistic reward task }\end{array}$ & $\begin{array}{l}\text { Tone discrimination training: operant testing chamber with two } \\
\text { levers, a food receptacle, and a speaker. Rodents discriminate } \\
\text { between two tone stimuli by pressing an associated lever. } \\
\text { Testing: ambiguous tone durations. Correct identification of one } \\
\text { tone (rich stimulus) is reinforced with a food pellet three times } \\
\text { more frequently than the other tone (lean stimulus) }\end{array}$ & $\begin{array}{l}\text { Response bias, discriminability, accuracy (\% correct), } \\
\text { reaction time }\end{array}$ & 250 \\
\hline $\begin{array}{l}\text { Forced swim test (Porsolt } \\
\text { forced swim test or } \\
\text { behavioral despair test) }\end{array}$ & Rodents are placed inside a cylindrical water tank & Time immobile & 251,252 \\
\hline Tail suspension & Rodents are hung by their tails & Time immobile & 253 \\
\hline Open field & $\begin{array}{l}\text { Square, rectangular, or circular enclosure that is bare or covered } \\
\text { with a thin layer of bedding }\end{array}$ & $\begin{array}{l}\text { Total locomotor activity, ambulatory locomotor activity, distance } \\
\text { traveled, frequency of rearing, frequency of sniffing }\end{array}$ & 254 \\
\hline Flinch-jump test & $\begin{array}{l}\text { Operant chamber in a ventilated, sound-attenuated cubicle with } \\
\text { a shock grid floor, speaker, and video camera. Shock titrations are } \\
\text { delivered in a series of ascending and descending intensities } \\
\text { based on the rodent's response }\end{array}$ & Flinch threshold, vocalization threshold, jump threshold & 53 \\
\hline Hot-plate test & $\begin{array}{l}\text { Rodents are placed in a glass beaker on a plate heated to a } \\
\text { constant temperature }\end{array}$ & Latency to flinch or raise hind paws & 255,256 \\
\hline Tail flick test & $\begin{array}{l}\text { The distal third of a rodent's tail is thermally stimulated with } \\
\text { radiant heat (e.g., focused light from a light bulb), immersion in } \\
\text { hot water, or direct contact with a heated surface }\end{array}$ & Latency to withdraw tail & 257 \\
\hline von Frey test & $\begin{array}{l}\text { von Frey filaments are applied to the plantar region of a rodent's } \\
\text { paw through a wire mesh floor. Stimulation continues in a series } \\
\text { of ascending and descending filament forces based on the } \\
\text { rodent's response }\end{array}$ & Paw withdrawal threshold & 258 \\
\hline Sucrose preference & $\begin{array}{l}\text { After habituation to two drinking bottles, one water bottle is } \\
\text { replaced with a } 1-2 \% \text { sucrose solution. Bottle positions (left vs. } \\
\text { right) are alternated each day to control for side-preference bias }\end{array}$ & $\%$ sucrose preference, $\%$ sucrose intake, $\%$ water intake & 259 \\
\hline $\begin{array}{l}\text { Intracranial self- } \\
\text { stimulation }\end{array}$ & $\begin{array}{l}\text { Operant chamber in a ventilated, light-attenuated and sound- } \\
\text { attenuated cubicle with a wheel or lever manipulandum on the } \\
\text { wall. Bipolar electrodes are implanted into a brain region that is } \\
\text { part of the reward system. Training: manipulandum response } \\
\text { following noncontingent stimulation prompts an identical } \\
\text { contingent stimulation. Testing: stimulations are delivered in a } \\
\text { series of ascending and descending intensities based on the } \\
\text { rodent's response }\end{array}$ & $\begin{array}{l}\% \text { baseline current-intensity threshold, response latency, number } \\
\text { of extra responses, number of time-out responses }\end{array}$ & 260,261 \\
\hline Social interaction test & $\begin{array}{l}\text { Two novel conspecific rodents (same sex, size, and age) interact } \\
\text { freely in an open field }\end{array}$ & $\begin{array}{l}\text { Time spent in active social interaction (sniffing, licking, close } \\
\text { following, allogrooming, crawling over the partner), number of } \\
\text { social interactions, time spent in social avoidance (escaping, } \\
\text { keeping the partner at distance with upright forepaws) }\end{array}$ & 262 \\
\hline $\begin{array}{l}\text { Social preference/ } \\
\text { avoidance test }\end{array}$ & $\begin{array}{l}\text { Open field with a wire cage centered against a wall of the arena. } \\
\text { One trial without a rodent in the cage (no target) and one trial } \\
\text { with a rodent in the cage (target) }\end{array}$ & $\begin{array}{l}\text { Time spent in the interaction zone with the target absent/ } \\
\text { present, time spent in the two corner zones opposite the wire } \\
\text { cage, social avoidance ratio }\end{array}$ & 263,264 \\
\hline Partner preference test & $\begin{array}{l}\text { Two boxes linked to a starting box. One female and male rodent } \\
\text { is tethered to the rear of a goal box }\end{array}$ & $\begin{array}{l}\text { Time spent with male/female, time spent in active social } \\
\text { interaction with male/female, number of visits to male/female }\end{array}$ & 265 \\
\hline $\begin{array}{l}\text { Social approach/ } \\
\text { avoidance test }\end{array}$ & $\begin{array}{l}\text { Two chambers of different widths connected by a sliding door. A } \\
\text { large conspecific rodent (stimulus) is enclosed in a compartment } \\
\text { of the large chamber, separated by a transparent perforated wall. } \\
\text { The sliding door is removed after a habituation phase in the } \\
\text { smaller chamber }\end{array}$ & $\begin{array}{l}\% \text { time spent in the large chamber compartment, number of } \\
\text { entries to the large chamber }\end{array}$ & 266 \\
\hline
\end{tabular}


Table 2 continued

\begin{tabular}{|c|c|c|c|}
\hline Behavioral test & Description & Measures & References \\
\hline $\begin{array}{l}\text { Three-chamber sociability } \\
\text { and social novelty test } \\
\text { (Crawley test) }\end{array}$ & $\begin{array}{l}\text { Three-chambered box connected by sliding doors and with one } \\
\text { wire cage in each side chamber. Habituation trial: rodent is } \\
\text { placed in the center chamber with obstructed access to side } \\
\text { chambers. Sociability test: novel conspecific rodent (same sex, } \\
\text { size, and age) is placed in one of the wire cages. Social novelty } \\
\text { test: another novel conspecific rodent is placed in the } \\
\text { opposite cage }\end{array}$ & $\begin{array}{l}\text { Time spent in empty chamber, time spent in social chamber } 1 \text {, } \\
\text { time spent in social chamber } 2 \text {, social interaction ratio, social } \\
\text { novelty preference index }\end{array}$ & 267 \\
\hline $\begin{array}{l}\text { Olfactory habituation and } \\
\text { dishabituation test }\end{array}$ & $\begin{array}{l}\text { Glass slides with drops of water (nonsocial odor) and two social } \\
\text { odors of diluted urine from different same-sex rodents are } \\
\text { sequentially presented into a cage. Three consecutive trials of } \\
\text { each odor are conducted }\end{array}$ & Time spent in direct olfactory investigation (sniffing) & 268 \\
\hline Criterion $E$ & Alterations in arousal and reactivity & & \\
\hline Object burying & $\begin{array}{l}\text { An unfamiliar object is placed on the surface of bedding } \\
\text { in a cage }\end{array}$ & $\%$ time spent manipulating object, \% time spent burying object & 224 \\
\hline Marble burying & $\begin{array}{l}\text { 10-20 glass marbles are spaced evenly on the surface of bedding } \\
\text { in a cage }\end{array}$ & $\begin{array}{l}\text { Number of marbles buried (to } 2 / 4 \text { their depth), latency to dig, } \\
\text { time spent digging, rearing count }\end{array}$ & 32,269 \\
\hline Acoustic startle response & $\begin{array}{l}\text { Cylindrical animal enclosure on a platform inside a ventilated, } \\
\text { sound-attenuated cabinet. Speakers produce a continuous } \\
\text { background noise and the acoustic stimuli. An acclimation } \\
\text { period is followed by startle noise trials }\end{array}$ & Startle amplitude, average startle response & 97,270 \\
\hline Prepulse inhibition & $\begin{array}{l}\text { Cylindrical animal enclosure on a platform inside a ventilated, } \\
\text { sound-attenuated cabinet. Speakers produce a continuous } \\
\text { background noise and the acoustic stimuli. An acclimation } \\
\text { period is followed by pulse-alone trials, prepulse + pulse trials, } \\
\text { and no stimulus trials in pseudorandom order }\end{array}$ & Startle amplitude, \% prepulse inhibition & 271 \\
\hline $\begin{array}{l}\text { Operant attentional set- } \\
\text { shifting tasks }\end{array}$ & $\begin{array}{l}\text { Operant chamber in a ventilated, sound-attenuated cubicle with } \\
\text { two operandi (e.g., nose-poke holes or levers) on each side of a } \\
\text { food dispenser and yellow lights. Correct responses are } \\
\text { reinforced with palatable food (e.g., sucrose solution or sucrose } \\
\text { pellets). Pretraining: rodents associate stimuli with reward. } \\
\text { Response discrimination reversal-Response discrimination } \\
\text { training: rodents respond on the operandum opposite to their } \\
\text { side bias. Response discrimination reversal: rodents respond on } \\
\text { the opposite operandum. Visual-cue-to-place set-shifting-Visual- } \\
\text { cue discrimination training: rodents respond on the illuminated } \\
\text { operandum. Shift to response discrimination: rodents respond } \\
\text { on the operandum opposite of their side bias, regardless of the } \\
\text { light's position }\end{array}$ & $\begin{array}{l}\text { Number of errors to criterion, number of errors over } 20 \text { trials, } \\
\text { total number of trials to criterion, number of error trials, number } \\
\text { of errors by type (pervasive, regressive, never-reinforced) }\end{array}$ & 272,273 \\
\hline
\end{tabular}

immediate and persistent (7-30 days post-stress) increased arousal in acoustic startle response (ASR) and anxiety-like behavior in the elevated-plus maze (EPM) tests compared to control rats that swam without submersion $^{43-45}$. Learning deficits in Morris water maze (MWM) spatial memory tasks, observed three weeks after trauma exposure, demonstrated the stressor's lasting negative effects on cognition ${ }^{44}$. However, interpretation of MWM results can be confounded by the re-exposure to water, a reminder of underwater trauma, that may influence task performance. Decreased plasma basal corticosterone (CORT) levels were found seven days after stress, indicating a lasting depression of HPA axis signaling following the trauma ${ }^{43}$. Based on successive performance in EPM and ASR, cut-off behavioral criteria demonstrated that the prevalence of maladaptive response to stress dropped from $91.6 \%$ of exposed Sprague-Dawley rats on day 1 , the acute phase, to a constant rate of $41.6 \%$ by day 7 through day 30 . Concomitantly, the prevalence of welladapted rats rose from $0 \%$ to $25 \%$ over days $1-3045$. This temporal pattern reaffirms that animals display an individual variation in response similar to humans ${ }^{46}$. That is, the initially large affected proportion of the exposed population decreases steadily with time as many individuals show a tendency toward symptom improvement. Some may present acute stress disorder and a minority develop PTSD. Behavioral profiling, validated by immunohistochemical assessments, uncovered three separate stress response phenotypes: an anxious, fear-based group (38\%), a co-morbid, fear-anhedonic group (15\%), and an exposed-unaffected group (47\%). In accordance with the high anxiety trait of the posttraumatic depression model ${ }^{47}$, enhanced pretrauma freezing correlated with posttrauma saccharin preference among fear-anhedonic phenotype rats, predicting anhedonia one month after exposure $^{48}$. Although its intensity cannot be easily controlled, advantages of underwater trauma as a PTSD model are its reproducible context and ethologically relevant stress.

\section{Single prolonged stress}

Single prolonged stress (SPS) involves sequential administration of three stressors-2-h restraint, 20-min forced swim, and diethyl ether anesthesia-with a 7-day or 14-day undisturbed sensitization before testing. According to time-dependent sensitization studies, the undisturbed 
incubation period is necessary for PTSD-like symptom manifestation ${ }^{49}$. Interestingly, studies observed most behavioral and cellular changes seven days after SPS or reexposure, indicating time-dependent and experiencedependent sensitization ${ }^{50}$. Consistent with findings in PTSD patients, neuronal apoptosis and autophagy dysregulation in the hippocampus, amygdala, and prefrontal cortex appeared one day after stress, suggesting that morphological changes precede behavioral alterations ${ }^{51}$. Combination of the three stressors is required for the PTSD phenotype, as combinations of any two does not induce all effects observed in the SPS paradigm ${ }^{52}$. As in underwater trauma, interpretation of forced swim and MWM test results is confounded by the re-exposure to water. Although age effects on SPS susceptibility have not been evaluated to date, maternal separation was found to strengthen adult SPS-induced increases in anxiety and contextual fear ${ }^{53}$. Early life exposure to SPS caused anxiety-like and depression-like behavior at postnatal day 32 (human early-adolescence), anxiety-like behavior at postnatal day 60 (human late-adolescence), followed by depression-like behavior (stress-susceptible) or no behavioral deficits (stress-resilient) at postnatal day 90 (human adulthood), suggesting that adaptations such as behavioral and cognitive switching occur at postnatal day $60^{54}$. The two studies of sex differences in fear extinction retention following SPS report conflicting results, with one observing no effect ${ }^{55}$ and the other noting deficits ${ }^{56}$. The finding that female rats express fear by darting rather than freezing indicates that freezing alone may be misleading and motivates reinterpretation of female rodent fear conditioning studies ${ }^{57}$. SPS increased the latency of pairhoused Sprague-Dawley females to approach a novel rat in the social preference/avoidance test, implying an anxious phenotype, but decreased the latency of single housed females, implying social support seeking ${ }^{58}$. The dexamethasone suppression test revealed an exaggerated negative feedback control of the HPA axis in SPS-exposed Sprague-Dawley males, but not in females ${ }^{59}$. SPS lacks ecological validity and its stressor intensity cannot be modified. However, an advantage of SPS as a PTSD model is its combination of stressors to produce a synergistic effect. For an extensive review of SPS, see Lisieski, Souza, and Yamamoto ${ }^{60-62}$.

\section{Social and psychological stressors}

Social and psychological stressors include social defeat and predator stress. Advantageous for their ecological validity and relevance to interpersonal assault traumas ${ }^{63}$, these stressors are widely utilized in differentiating individual variability. While predator stress can be conducted on both sexes, social defeat is challenging to model in female rodents because they tend not to defend territories with aggressive behavior. When using direct exposure to a resident rodent or predator, reproducibility of the stressor can be challenging due to variation in rodent and predator aggression. If the social and psychological nature of these stressors causes physical injuries, behavioral measures may then reflect physical rather than neurological driven effects.

\section{Social defeat stress}

Social defeat stress (SDS) is used in rodent models of depression $^{64}$ and PTSD. There are three variations of SDS: resident-intruder, witnessed social defeat stress (trauma witness or vicarious social defeat), and cagewithin-cage resident-intruder. While in the residentintruder paradigm, an experimental rodent (intruder) is exposed daily (5-10 days; $5-10 \mathrm{~min}$ per day) to a novel dominant conspecific (resident) ${ }^{65,66}$, witnessed social defeat stress is induced by daily inescapable sensory contact with novel rodents undergoing physical social defeat ${ }^{67}$. In both procedures, subordination may then be reinforced through $24 \mathrm{~h}$ of sensory (visual, olfactory, and auditory) contact with the resident, separated by perforated screen. The cage-within-cage resident-intruder paradigm introduces rodents to sensory contact with novel residents for 6-h sessions that include one to three 1 -min unpredictable physical contact periods ${ }^{68}$. Since territoriality is established in sufficient living space and enhanced in the presence of a sexual partner and sexual experience, the intruder is either introduced to an individually housed resident or replaces a cohabitating partner in the resident cage ${ }^{69}$. Intruders with lower body weights than residents are frequently used to guarantee intruder defeat ${ }^{66}$. Aggressive behaviors, different between male and female rodents, are characterized by attacking, pushing, aggressive grooming, chasing, pinning, and upright or lateral dominant postures ${ }^{70}$. Depression models employ chronic SDS, with stress repeated for 10 days to five weeks. It has, however, been suggested that chronic SDS may not only be a depression model, but may be more appropriately used to simulate the depression, anxiety, and social avoidance dimensions of PTSD ${ }^{71}$.

Male rodents exposed to resident-intruder social defeat manifest a persistent behavioral syndrome. The social preference/avoidance test categorized $50-70 \%$ of exposed C57BL/6 J mice as susceptible to stress ${ }^{65,72}$. Interestingly, social rank predicted this individual variability through a link between response strategy and outcome, showing that dominant mice were more susceptible than subordinate mice $^{73}$. Preexisting individual differences in the peripheral immune system also predicted stress susceptibility ${ }^{74}$. Morning CORT levels showed no changes among groups at day 11, but decreased in susceptible mice and increased in resilient mice at day 39 after social defeat ${ }^{72}$. In another study, stress resilience was associated with the emergence of the gram-positive bacteria Bifidobacterium. This finding is relevant to clinical applications as gut microbiota dysbiosis 
is found in patients with PTSD $^{75}$. Many studies have also shown that environmental enrichment promotes adaptive behavior and brain function. Enriched environmental housing before social defeat conferred stress resiliency. Further investigation, through lesion of the infralimbic cortex, illustrated that the ventromedial prefrontal cortex was involved in the acquisition of protective effects ${ }^{76}$. Extending this observation, optogenetic modulation of neuron projections to/from the ventromedial prefrontal $\operatorname{cortex}^{77}$, ventral tegmental area ${ }^{78,79}$, nucleus accumbens ${ }^{80}$, and dorsal raphe nucleus ${ }^{81}$, key nodes of PTSD circuitry, exerted antidepressant-like effects in susceptible mice.

Female-female agoniztic behaviors show low levels of direct attack in resident-intruder confrontations compared to inter-male aggression, limiting studies exploring the effects of social defeat in female rodents ${ }^{70}$. Furthermore, male behavior towards female versus male intruders is not similarly motivated and results in fewer attacks. As such, resident-intruder pairings are frequently same-sex conspecifics. The rarity of female aggressive behavior has been addressed through using lactating dams $^{82}$, aggressive species such as California mice and Syrian hamsters ${ }^{83,84}$, mediobasal hypothalamic lesions ${ }^{85}$, as well as testosterone treatment in neonatal ${ }^{86}$ and ovariectomized adult female rodents ${ }^{87,88}$. Female CD-1 mice exposed to lactating dams displayed elevated anxiety in the EPM, with more pronounced effects two weeks, but not $2 \mathrm{~h}$, after social defeat ${ }^{71}$. Although qualitatively different from male SDS, recent studies have induced male aggression toward females through application of male odorants on females ${ }^{89}$ and chemogenetic activation of the ventrolateral subdivision of the ventromedial hypothalamus in males ${ }^{90}$. The limited number of female rodent studies using similar species, methodologies, and behavioral tests complicates result comparison. In addition, cross-sex comparison is contingent upon proof of equivalent attack magnitude toward males and females. While care is taken to minimize severe injuries, behavioral measures may be compromised when the social nature of resident-intruder and cage-within-cage resident-intruder paradigms is mixed with the stress of physical injury. SDS is also limited by the potential for adaptation to its predictable repeated stress. Although the stressor type cannot be varied, its predictability could be reduced by exposing rodents to novel residents at different times each day for different stress durations. For review of social defeat, see Hammels ${ }^{91}$.

\section{Predator stress}

Predator stress models, prioritizing ecological validity, expose rodents to species-relevant predators or their scents. Variations of this stressor include predator exposure stress, predator-based psychosocial stress (PPS), and predator scent stress (PSS).
In the predator exposure stress model, rodents are acclimated for $5 \mathrm{~min}$ in an inescapable exposure environment, followed by a 5-60 min exposure to an unprotected/protected (subject is free/caged) cat ${ }^{92,93}$ or ferret ${ }^{94}$. While initial acute cat exposure studies assessed overall behavior through tests of risk assessment, anxiety, and $\operatorname{arousal}^{92}$, later reports also found avoidance of traumareminder in the open field test ${ }^{95}$, with spatial memory retention impairments in the MWM and radial-arm water maze ${ }^{93,96}$. Like SPS, exposure enhanced dexamethasone suppression of CORT in Sprague-Dawley males, but not in females ${ }^{59}$. In addition, acute ferret exposure in Sprague-Dawley rats produced sensorimotor gating abnormalities in prepulse inhibition ${ }^{94}$. Out of the exposed Sprague-Dawley rats, 25.3\% developed PTSD-like behavioral and endocrine dysregulation ${ }^{96}$. Sex differences in vulnerability were test specific, noted in EPM, open field, and ASR measures. Sex differences were also identified in hole-board and light-dark box measures which were unaffected by exposure ${ }^{95,97}$. Persistent behavioral changes, some lasting at least three weeks after exposure, corresponded to changes in the amygdala, medial prefrontal cortex, and hippocampus. These structural and molecular changes are consistent with brain regions involved in PTSD $^{93,95,98,99}$. However, given predator exposure's variable cat-rodent interaction and the challenge of controlling cat aggression, both cat and rodent behavior must be assessed. For review of predator exposure, see ${ }^{100}$.

The PPS model, composed of acute and chronic components, combines $1 \mathrm{~h}$ of acute immobilization during novel cat exposure on days one (during the light cycle) and 11 (during the dark cycle), with 31 days of chronic unstable housing conditions to produce a risk factor synergistic effect. Following observations that rodents directed their postures away from cats, providing them with an element of control over confrontations, immobilization was included in this model as an analog to the sense of helplessness prominent in PTSD. Repeated cat exposure was included to (1) apply to people who develop PTSD only after multiple traumas; (2) mimic intrusive trauma reminders by forcing rodents to re-experience the original stress; (3) mimic the unpredictability of re-experiences (light or dark cycle); and (4) augment stress-induced changes. Further increasing symptom prevalence, daily randomized housing conditions were included to mimic chronic mild stress and lack of social support ${ }^{101}$. Three weeks after the second predator exposure, all stressed Sprague-Dawley rats exhibited PTSDlike sequelae. PPS also caused reduced growth rate, thymus weight, and basal glucocorticoid levels, as well as increased adrenal gland weight and physiological reactivity to an acute stressor ${ }^{101-103}$. Some effects were still observed more than four months after stress onset ${ }^{104}$. Neurotransmitter changes, such as greater norepinephrine and reduced serotonin levels in the hippocampus and prefrontal cortex, are in 
concert with human PTSD research ${ }^{105-107}$. This paradigm was also shown to induce sex-dependent cardiovascular alterations with notable male and ovariectomized female increases in myocardial sensitivity to ischemic injury. Stressed female rats displayed anxiety-like behavior in the EPM and open field, irrespective of estrous stage or ovariectomy condition. However, stressed female rats did not demonstrate physiological effects other than a reduced growth rate ${ }^{108,109}$. For review of PPS, see Zoladz ${ }^{110}$.

The PSS model involves a 5 to 15 -min inescapable exposure to fox/bobcat urine ${ }^{111}$, soiled cat litter ${ }^{112}$, a catworn collar/cloth ${ }^{113}$, a ferret cloth ${ }^{114}$, or trimethylthiazoline (TMT), a synthetic compound isolated from fox feces ${ }^{115}$. Similar findings in successive ferret and cat cloth exposures confirmed failure of stress-habituation ${ }^{114,116}$. Moreover, different amounts of $\mathrm{TMT}^{117}$ and sizes of cloth impregnated with cat scents ${ }^{118}$ elicited fear-related behavior in a dose-dependent manner. After application of median split criteria, the incidence of susceptible TMT-exposed Sprague-Dawley rats ranged from 14 to $21.8 \%{ }^{119}$. Similarly, after cut-off behavioral criteria, extreme behavioral responses (PTSD-like) to soiled cat litter were observed among $50 \%$ of Lewis, 10\% of Fischer F344, and 25\% of Sprague-Dawley rats $^{112}$. Although sensitive to strain differences, cut-off behavioral criteria did not distinguish PTSD prevalence among male and female Sprague-Dawley rats ${ }^{120}$. In both sexes, extreme behavioral response rats displayed inhibited cardiac autonomic system habituation and recovery after exposure $^{121}$. Early life stress increased vulnerability to cardiac autonomic dysfunction, and blunted basal CORT pulse amplitude predicted post-exposure PTSD susceptibility $^{122,123}$. Avoidance of bobcat urine-paired context predicted post-stress thermal hyperalgesia in Wistar rats with high stress reactivity ${ }^{111}$. Interestingly, resting-state functional magnetic resonance imaging (rsfMRI) noninvasively detected prolonged neuroadaptation within the amygdala-medial prefrontal cortex circuit in Long-Evans rats exposed to cat collar ${ }^{113}$. Another study found that preexisting functional connectivity in olfactory and stressrelated neural circuits might predispose animals to differential stress responses, linked to PTSD susceptibility, during fox urine exposure. Susceptible rats exhibited less freezing, but greater avoidance of fox urine, and displayed a prolonged CORT response, as well as higher anxiety long after exposure $^{124}$. These findings indicate the importance of analyzing behavior during exposure. A high-dose of CORT injected subcutaneously $1 \mathrm{~h}$ before soiled cat litter exposure reduced the prevalence of extreme behavioral responses from $50 \%$ to $8 \%$ in Lewis rats, indicating that elevated CORT levels before acute stress prevent later stress effects $^{112}$. Analogous to clinical trial results, high-dose CORT administered $1 \mathrm{~h}$ after stress reduced the prevalence of PTSD-like rats, reversing extreme behavioral disruptions along with molecular and morphological measures in the hippocampal dentate gyrus. This evidence supports the use of high-dose CORT in trauma care and suggests that there is a treatment "window of opportunity" early after trauma ${ }^{125}$. Combined, these observations indicate the protective effects of glucocorticoids against the development of PTSD. Sleep deprivation for $6 \mathrm{~h}$ during the first resting phase after PSS attenuated PTSD-like behaviors in EPM, ASR, and hippocampal expression of glucocorticoid receptors, demonstrating an avenue for secondary prevention of stress-related clinical disorders ${ }^{126,127}$. Since predator scent can impregnate testing rooms and influence control animals, careful handling and stressing under a fume hood is advised. Olfactory cues such as dosage of a scent are challenging to control because olfaction is variable and driven by perception. An advantage of PSS as a PTSD model is its ecologically relevant stress, as rodents use the olfactory sensory system for survival-related behaviors ${ }^{128}$. For review of PSS, see Cohen and Staples ${ }^{129,130}$.

\section{Translational studies of PTSD}

Established stress paradigms that induce PTSD-like behavioral and biological phenotypes are available (Table 1). However, since stressor severity varies, stressful experiences that are within a rodent's coping capacity should be distinguished from traumatic experiences that are beyond its coping capacity. Rodent behavioral tests, mimicking the tests conducted in humans, are used to assess stress effects and allow researchers to make inferences about rodent psychology (Table 2). Although all stress models produce lasting general anxiety or depression effects, variety in behavior robustness makes each paradigm effective at targeting specific constructs. Behavioral tests and neurobiological changes are used to evaluate an animal model's representation of the human disorder, satisfying DSM-5 PTSD symptom clusters (Tables 3, 4), validity criteria (Table 5), and Yehuda and Antelman's criteria (Table 6). Unlike for the DSM-5, no criteria have been established to assess how well an animal model meets validity or Yehuda and Antelman's criteria. Gaps in literature were addressed as no one model has been proven to satisfy all criteria.

Many behavioral tests were developed and validated in rats, and only later were adapted for mice. Rats were traditionally the species of choice in preclinical research for their performance in operant tasks and their larger size that facilitates application of invasive techniques, as well as toxicity tests of compounds. Mice, on the other hand, are advantageous for their ease of genetic modification, breeding, and group housing. Following the increasing use of mice, behavioral tests were translated into mouse versions, but with mixed success ${ }^{131,132}$. Therefore, the utility of mouse models is contingent on the availability of more behavioral tests that are optimized for use in mice. 
Table 3 Evaluation of reviewed animal models against DSM-5 criteria for PTSD-effects in males ${ }^{6}$.

\begin{tabular}{|c|c|c|c|c|c|c|c|c|}
\hline & \multirow{2}{*}{$\begin{array}{l}\text { Criterion B: } \\
\text { intrusion } \\
\text { Physiological } \\
\text { reactions to } \\
\text { trauma } \\
\text { reminders }\end{array}$} & \multirow{2}{*}{$\begin{array}{l}\text { Criterion C: } \\
\text { avoidance of } \\
\text { trauma related } \\
\text { stimuli } \\
\text { Increased } \\
\text { avoidance }\end{array}$} & \multicolumn{2}{|c|}{$\begin{array}{l}\text { Criterion D: negative alterations in cognition } \\
\text { and mood }\end{array}$} & \multicolumn{3}{|c|}{$\begin{array}{l}\text { Criterion E: alterations in arousal and } \\
\text { reactivity }\end{array}$} & \multirow{2}{*}{$\begin{array}{l}\text { Criterion F: } \\
\text { lasting } \\
\text { symptoms } \\
\text { Symptoms } \\
\text { present }\end{array}$} \\
\hline & & & Cognitive alterations & Mood alterations & $\begin{array}{l}\text { Increased } \\
\text { arousal }\end{array}$ & $\begin{array}{l}\text { Concentration } \\
\text { problems }\end{array}$ & $\begin{array}{l}\text { Sleep } \\
\text { disturbance }\end{array}$ & \\
\hline $\begin{array}{l}\text { Physical stress } \\
\text { Electric shock }\end{array}$ & $\begin{array}{l}\text { Contextual and } \\
\text { cued } \\
\text { reminders }{ }^{25,224}\end{array}$ & $\begin{array}{l}\text { EPM, OF, CODA, } \\
\text { conditioned object } \\
\text { avoidance, NSF, } \\
\text { modified hole } \\
\text { board }^{28,234,235,274}\end{array}$ & $\mathrm{MWM}^{275}$ & $\begin{array}{l}\text { Tail flick, SAAT, SI, } \\
\text { FST }^{27,28,266}\end{array}$ & $\begin{array}{l}\text { Object } \\
\text { burying, } \\
\text { ASR }^{25,224}\end{array}$ & & $\mathrm{EEG}^{234}$ & $>$ Month $^{24,276}$ \\
\hline Immobilization stress & $\begin{array}{l}\text { Contextual } \\
\text { reminder }^{34,35}\end{array}$ & $\begin{array}{l}\text { EPM, OF, hole board, } \\
\text { mirror chamber, } \\
\operatorname{LDB}^{31,34,277-279}\end{array}$ & $\begin{array}{l}\text { FCFE, MWM, NOR, Y-maze } \\
\text { spontaneous alteration } \\
\text { test }{ }^{34,280,281}\end{array}$ & $\begin{array}{l}\text { Incentive salience, SP, } \\
\mathrm{FST}^{38,278,282}\end{array}$ & $\begin{array}{l}\text { ASR, } \\
\mathrm{MB}^{32,283}\end{array}$ & & $\begin{array}{l}\mathrm{EEG}, \mathrm{EMG} \\
\mathrm{EOG}^{33}\end{array}$ & $>1$ Week $^{31}$ \\
\hline Underwater trauma & $\begin{array}{l}\text { Contextual } \\
\text { reminder }^{48}\end{array}$ & $\begin{array}{l}\text { EPM, hole board, } \\
\mathrm{OF}^{43,284,285}\end{array}$ & DCOC, MWM ${ }^{44,248}$ & $\mathrm{SP}^{48}$ & $\mathrm{ASR}^{45}$ & & & $>3$ Weeks $^{44}$ \\
\hline $\begin{array}{l}\text { Single } \\
\text { prolonged stress }\end{array}$ & Cued reminder ${ }^{286}$ & $\begin{array}{l}\text { Conditioned taste } \\
\text { aversion, OF, EPM, } \\
\text { elevated T-maze, } \\
\text { LDB, cliff } \\
\text { avoidance } \\
290\end{array}$ & $\begin{array}{l}\text { NOR, FCFE, RAWM, } \\
\text { MWM }^{51,52,54,291,292}\end{array}$ & $\begin{array}{l}\text { Three-chamber sociability } \\
\text { and social novelty test, } \\
\text { flinch-jump, hot-plate, SP, } \\
\text { FST, von Frey }{ }^{53,287,292-294}\end{array}$ & $\begin{array}{l}\text { ASR, } \\
\mathrm{MB}^{295,296}\end{array}$ & Set-shifting ${ }^{273}$ & $\mathrm{EEG}, \mathrm{EMG}^{297}$ & $>$ Month ${ }^{54,289,293}$ \\
\hline $\begin{array}{l}\text { Social defeat stress } \\
\text { Resident-intruder } \\
\text { social defeat }\end{array}$ & $\begin{array}{l}\text { Contextual } \\
\text { reminder }\end{array}$ & $\begin{array}{l}\text { EPM, LDB, } \\
E^{\prime} M^{72,73,298}\end{array}$ & $\begin{array}{l}\text { Response bias probabilistic } \\
\text { reward task, MWM, Barnes } \\
\text { maze, step-through } \\
\text { inhibitory avoidance, FCFE, } \\
\text { RAWM, NOR, Y-maze } \\
\text { recognition memory test, T- } \\
\text { maze continuous alteration } \\
\text { task }\end{array}$ & $\begin{array}{l}\text { SPAT, three-chamber } \\
\text { sociability test, intracranial } \\
\text { self-stimulation, SAAT, SP, } \\
\text { FST, OF, tail suspension, } \\
\text { olfactory habituation- } \\
\text { dishabituation } \\
310\end{array}$ & $\mathrm{ASR}^{311}$ & & $\mathrm{EEG}, \mathrm{EMG}^{312}$ & $>$ Month $^{72}$ \\
\hline $\begin{array}{l}\text { Witnessed } \\
\text { social defeat }\end{array}$ & $\begin{array}{l}\text { Contextual } \\
\text { reminder }^{20}\end{array}$ & EPM, $\mathrm{LDB}^{67,313}$ & RAWM $^{313}$ & $\begin{array}{l}\text { Three-chamber sociability } \\
\text { test, OF, SPAT, SP, } \\
\text { FST }^{67,313,314}\end{array}$ & & & & $>$ Month $^{315}$ \\
\hline $\begin{array}{l}\text { Cage-within-cage } \\
\text { resident-intruder } \\
\text { social defeat }\end{array}$ & $\begin{array}{l}\text { Contextual } \\
\text { reminder }^{68,316}\end{array}$ & Partition test ${ }^{68}$ & $\begin{array}{l}\text { Y-maze spontaneous } \\
\text { alteration test }{ }^{242}\end{array}$ & FST, tail suspension ${ }^{317}$ & & & & $>$ Month $^{68}$ \\
\hline $\begin{array}{l}\text { Predator stress } \\
\text { Predator } \\
\text { exposure stress }\end{array}$ & Cued reminder $^{95}$ & $\begin{array}{l}\text { EPM, hole board, } \\
\text { LDB, elevated T- } \\
\text { maze, OF } \text { OF, }^{22,95,318}\end{array}$ & MWM, RAWM ${ }^{93,96}$ & $\mathrm{Sl}^{92}$ & $\begin{array}{l}\text { ASR, } \\
\mathrm{PPI}^{94,97}\end{array}$ & & & $>3$ Weeks $^{92}$ \\
\hline $\begin{array}{l}\text { Predator-based } \\
\text { psychosocial stress }\end{array}$ & $\begin{array}{l}\text { Contextual and } \\
\text { cued } \\
\text { reminders }^{102}\end{array}$ & $\mathrm{EPM}^{101}$ & NOR $^{101}$ & & ASR $^{101}$ & & & $>$ Month $^{104}$ \\
\hline Predator scent stress & $\begin{array}{l}\text { Contextual } \\
\text { reminder }^{111,119,319}\end{array}$ & $\begin{array}{l}\text { EPM, territory } \\
\text { discrimination, LDB, } \\
\text { OF, hole } \\
\text { board }^{112,116,129,320,321}\end{array}$ & MWM, DCOC, NOR ${ }^{115,248,322}$ & $\begin{array}{l}\text { Partner preference, } \\
\text { Hargreaves test, } \\
\mathrm{SI}^{111,116,129}\end{array}$ & $\begin{array}{l}\text { PPI, } \\
\mathrm{MB}^{112,124}\end{array}$ & & $\begin{array}{l}\mathrm{EEG}_{1} \mathrm{EMG} \\
\mathrm{LFP}^{319}\end{array}$ & $>$ Month $^{122}$ \\
\hline
\end{tabular}

More specific behavioral tests should be incorporated into batteries to address gaps in PTSD research. Since sucrose preference does not distinguish between affective response and motivation, more specific tests are needed such as facial reactivity analysis and measurements of reward-related ultrasonic vocalizations ${ }^{133,134}$. Other possible attention assessments that have not been conducted in the context of PTSD include the signal detection test with blank trials for sustained attention and multiplechoice serial reaction time test for sustained and selective attention $^{135}$. The resident-intruder test has been used to assess irritability and aggression. However, this test is not listed in Table 2 because it incorporates the unclear stress effects of novel social interaction and could influence later behavioral time points.

One unrealized strength of rodent models of PTSD is in the discovery, development, and testing of effective pharmacological treatments. Historically, pharmaceutical companies did not invest in innovative drug discovery programs because modifying approved medications, particularly selective serotonin reuptake inhibitor (SSRI) antidepressants, was less time-consuming and more profitable $^{136}$. While the SSRIs sertraline (Zoloft) and paroxetine (Paxil, Paxil CR, Brisdelle, and Pexeva), are the only medications approved for PTSD by the Food and Drug Administration (FDA) to date, off-label pharmacological treatments include fluoxetine (Prozac, Prozac Weekly, and Sarafem) and venlafaxine (Effexor XR) ${ }^{137-}$ 140. These drugs were tested in PTSD patients because of their effectiveness in treating depression. Many provide relief in patients, yet no medications have been approved to promote resilience. Therefore, pharmacotherapy is currently recommended as an adjunctive or next-line treatment to trauma-focused psychotherapy ${ }^{139,141}$. Interestingly, the two medications that are indicated for PTSD treatment, sertraline and paroxetine, and the two most promising drug candidates, ketamine and 3,4-methylenedioxymethamphetamine-assisted psychotherapy, did 
Table 4 Evaluation of reviewed animal models against DSM-5 criteria for PTSD-Effects in females ${ }^{6}$.

\begin{tabular}{|c|c|c|c|c|c|c|c|c|}
\hline & \multirow{2}{*}{$\begin{array}{l}\text { Criterion B: } \\
\text { intrusion } \\
\text { Physiological } \\
\text { reactions to } \\
\text { trauma } \\
\text { reminders }\end{array}$} & \multirow{2}{*}{$\begin{array}{l}\text { Criterion C: } \\
\text { avoidance of } \\
\text { trauma related } \\
\text { stimuli } \\
\text { Increased } \\
\text { avoidance }\end{array}$} & \multicolumn{2}{|c|}{$\begin{array}{l}\text { Criterion D: negative alterations in } \\
\text { cognition and mood }\end{array}$} & \multicolumn{3}{|c|}{$\begin{array}{l}\text { Criterion E: alterations in arousal and } \\
\text { reactivity }\end{array}$} & \multirow{2}{*}{$\begin{array}{l}\text { Criterion F: } \\
\text { lasting } \\
\text { symptoms } \\
\text { Symptoms } \\
\text { present }\end{array}$} \\
\hline & & & $\begin{array}{l}\text { Cognitive } \\
\text { alterations }\end{array}$ & Mood alterations & $\begin{array}{l}\text { Increased } \\
\text { arousal }\end{array}$ & $\begin{array}{l}\text { Concentration } \\
\text { problems }\end{array}$ & $\begin{array}{l}\text { Sleep } \\
\text { disturbance }\end{array}$ & \\
\hline $\begin{array}{l}\text { Physical stress } \\
\text { Electric shock }\end{array}$ & $\begin{array}{l}\text { Contextual } \\
\text { reminder }^{26,276,323}\end{array}$ & EPM, LDB ${ }^{276,323}$ & & $\mathrm{Sl}^{323}$ & & & & $\overrightarrow{\text { Month }}{ }^{276,323}$ \\
\hline Immobilization stress & $\begin{array}{l}\text { Contextual } \\
\text { reminder }\end{array}$ & & & Incentive salience ${ }^{38}$ & & & & $>1$ Week $^{41}$ \\
\hline \multicolumn{9}{|l|}{ Underwater trauma } \\
\hline $\begin{array}{l}\text { Single } \\
\text { prolonged stress }\end{array}$ & & EPM $^{324}$ & $\mathrm{FCFE}^{56}$ & $\begin{array}{l}\text { FST, SP, SPAT, von } \\
\text { Frey }\end{array}$ & & & & $\begin{array}{l}>1 \\
\text { Week }^{56,294}\end{array}$ \\
\hline $\begin{array}{l}\text { Social defeat stress } \\
\text { Resident-intruder } \\
\text { social defeat }\end{array}$ & & $\mathrm{EPM}^{71,89,90}$ & & $\begin{array}{l}\text { SP, FST, SPAT, olfactory } \\
\text { habituation- } \\
\text { dishabituation } \\
89,310,325,326\end{array}$ & $\mathrm{ASR}^{326}$ & & & $>$ Month $^{310}$ \\
\hline $\begin{array}{l}\text { Witnessed } \\
\text { social defeat }\end{array}$ & $\begin{array}{l}\text { Contextual } \\
\text { reminder }^{327}\end{array}$ & $\mathrm{EPM}^{328}$ & & $\begin{array}{l}\text { SP, FST, SAAT, tail } \\
\text { suspension } \\
327,328\end{array}$ & & & & $>1$ Week $^{328}$ \\
\hline \multicolumn{9}{|l|}{$\begin{array}{l}\text { Cage-within-cage } \\
\text { resident-intruder } \\
\text { social defeat }\end{array}$} \\
\hline $\begin{array}{l}\text { Predator stress } \\
\text { Predator } \\
\text { exposure stress }\end{array}$ & $\begin{array}{l}\text { Contextual and } \\
\text { cued } \\
\text { reminders } \\
95,329\end{array}$ & EPM, OF, LDB ${ }^{95,97}$ & RAWM $^{330}$ & & $\mathrm{ASR}^{97}$ & & & $>2$ Weeks $^{95}$ \\
\hline $\begin{array}{l}\text { Predator-based } \\
\text { psychosocial stress }\end{array}$ & & EPM, OF ${ }^{108}$ & & & & & & \\
\hline Predator scent stress & & $\mathrm{EPM}^{120,331}$ & MWM $^{120}$ & & $\mathrm{ASR}^{120,331}$ & & & $>1$ Week $^{120}$ \\
\hline
\end{tabular}

not emerge from basic research ${ }^{142}$. In addition, only some drugs have been tested in rodent models to study their targets and mechanisms of action (Table 5). One explanation for their mechanism is that medications may enhance psychotherapy's efficacy to engage biological targets associated with recovery or resilience ${ }^{142}$. Alternatively, medications may distinguish the PTSD biological subtypes that respond to their targets ${ }^{143,144}$. Now that rodent models of PTSD are more validated and have been refined over the last 20 years, their use could elucidate human psychopathology and further reveal mechanisms driving recovery.

In rodents, as in humans, different traumas can cause different PTSD-like symptoms. Each with their advantages and disadvantages, there is no single model that serves all purposes. All reviewed animal models have phenomenological similarities to PTSD and satisfy face validity. Peripheral biologic correlates of PTSD have been evaluated for all stressors, generally meeting construct validity. For example, there are strong hypotheses regarding the neural mechanisms involved in PTSD, such as hyperactivity of the corticotropin-releasing hormone system, that have been verified in rodents ${ }^{145,146}$. However, because the biological basis of PTSD is not well understood, work needs to be done to define clear conditions for construct validity. Although preclinical research on traumatic stress has not yet resulted in drastic improvements in PTSD treatments, most models test pharmacological treatment options, providing them with predictive validity and potential for use in the development of clinical therapy. Given these results, more wellstudied models such as electric shock and single prolonged stress may fit more criteria, but lack demonstration of multiplex behavioral outcomes in individual animals. While DSM-5, validity, and Yehuda and Antelman's criteria each capture some of PTSD's complexity, consideration of all three may be used to improve categorization of a rodent model's trauma effects and inform stress paradigm selection. More accurately capturing the disorder in any individual model is critical, but overly limiting the types of models studied may be counterproductive in developing a comprehensive understanding of such a variable disorder.

\section{Challenges}

\section{Symptom comorbidity}

Symptom comorbidity complicates PTSD diagnosis and treatment. Although rodent models are useful for symptom analysis, there are limitations to generalizing stress in rodents to PTSD in humans since clinical diagnosis heavily relies on a patient interview rather than quantitative diagnostic measures. Individuals with PTSD are $80 \%$ more likely than those without PTSD to have symptom comorbidity. Symptoms such as avoidance, anhedonia, and exaggerated startle response may overlap with symptoms of other mental illnesses (e.g., depressive, bipolar, anxiety, or substance use 
Table 5 Evaluation of reviewed animal models against validity criteria for animal models of human mental disorders ${ }^{7}$.

\begin{tabular}{|c|c|c|c|}
\hline & $\begin{array}{l}\text { Face validity: } \\
\text { represents symptoms } \\
\text { of the human } \\
\text { disorder }\end{array}$ & $\begin{array}{l}\text { Construct validity: represents the cellular } \\
\text { and molecular mechanisms in the human } \\
\text { patient (homologous constructs) }\end{array}$ & $\begin{array}{l}\text { Predictive validity: demonstrates successful use of } \\
\text { effective pharmacological treatments in human } \\
\text { patients, discriminates between effective/ } \\
\text { ineffective treatments }\end{array}$ \\
\hline $\begin{array}{l}\text { Physical stress } \\
\text { Electric shock }\end{array}$ & 234,323 & 274 & Paroxetine, fluoxetine, sertraline ${ }^{28,332,333}$ \\
\hline Immobilization stress & 34,41 & $31,33,42$ & Venlafaxine ${ }^{334}$ \\
\hline Underwater trauma & 44,45 & 48 & \\
\hline $\begin{array}{l}\text { Single } \\
\text { prolonged stress }\end{array}$ & 53,324 & 61,62 & Paroxetine 335,336 \\
\hline $\begin{array}{l}\text { Social defeat stress } \\
\text { Resident-intruder } \\
\text { social defeat }\end{array}$ & 89,307 & $72,91,312$ & Fluoxetine, sertraline ${ }^{264,337}$ \\
\hline $\begin{array}{l}\text { Witnessed } \\
\text { social defeat }\end{array}$ & 313,328 & 74 & Fluoxetine $^{67}$ \\
\hline $\begin{array}{l}\text { Cage-within-cage } \\
\text { resident-intruder } \\
\text { social defeat }\end{array}$ & 68 & 338 & \\
\hline $\begin{array}{l}\text { Predator stress } \\
\text { Predator } \\
\text { exposure stress }\end{array}$ & 96,97 & 98,339 & Fluoxetine $e^{340}$ \\
\hline $\begin{array}{l}\text { Predator-based } \\
\text { psychosocial stress }\end{array}$ & 101 & 110 & Sertraline ${ }^{341}$ \\
\hline Predator scent stress & 129,130 & 113,331 & Sertraline $e^{342}$ \\
\hline
\end{tabular}

disorders), making it difficult to attribute them to a specific PTSD model ${ }^{6}$. This creates challenges in distinguishing animal models of PTSD from other psychiatric illness models. The criteria used in the development and study of PTSD models will continue to evolve as scientific understanding of PTSD grows and the DSM is updated. Nevertheless, longitudinal studies are used to develop animal models with relevant PTSD symptom domains and to test causal factors in symptom development.

\section{Anthropomorphism}

The anthropomorphizing that can occur when uniquely human characteristics are attributed to animals is a danger of animal models and complicates their translatability. Many diagnostic criteria of mental disorders are subjective, involving thoughts, memories, and their interpretations. Such criteria as intrusive thoughts, emotional blunting, and cognitive distortion cannot be measured in animals without the danger of excessive anthropomorphism. Therefore, research is limited to observable behaviors with quantifiable measures, many of which are detailed in Table 2. However, even these measures have limitations, since rodent behavioral tests often do not directly correlate to human tests. The urgency to perform "translational" work can cause research groups to exaggerate a treatment's effects and scientific foundation, ultimately hindering treatment development. Prolonged exposure, for example, is a cognitive behavioral therapy that only works for some patients and may not be based on fear extinction, yet extinction learning is so robust and explainable in animals that it is used to justify the treatment's mechanism ${ }^{147}$. From the "translational" research opportunity and ease of modeling fear acquisition and extinction, this single aspect of PTSD has become more significant than it is clinically ${ }^{148}$. Anthropomorphizing can also result in data overinterpretation. For example, rodents that demonstrate escape or freezing behavior have been referred to as anxious rather than, more appropriately, exhibiting anxiety-related or anxiety-like behavior $^{149}$. Further, this anthropomorphizing can lead to misleading interpretations of behavior, as it has been shown that behaviors like freezing are not simple quantitative measures of fear or anxiety as they are often utilized $^{150}$. Therefore, to optimize the study of PTSD, rodent models should be empirically based, without anthropomorphic inference. 
Table 6 Evaluation of reviewed animal models against Yehuda and Antelman's criteria for animal models of PTSD ${ }^{8}$.

\begin{tabular}{|c|c|c|c|c|c|}
\hline & $\begin{array}{l}\text { Induces biological } \\
\text { and behavioral } \\
\text { sequelae of PTSD }\end{array}$ & $\begin{array}{l}\text { Produces PTSD-like } \\
\text { sequelae in a dose- } \\
\text { dependent manner }\end{array}$ & $\begin{array}{l}\text { Produces biological alterations } \\
\text { that persist or become more } \\
\text { pronounced over time }\end{array}$ & $\begin{array}{l}\text { Induces } \\
\text { bidirectional } \\
\text { biobehavioral } \\
\text { alterations }\end{array}$ & $\begin{array}{l}\text { Produces } \\
\text { interindividual } \\
\text { variability in } \\
\text { response }\end{array}$ \\
\hline $\begin{array}{l}\text { Physical stress } \\
\text { Electric shock }\end{array}$ & 234,323 & 28,224 & 323 & 332 & 28 \\
\hline Immobilization stress & 34,41 & 30,343 & 344 & & \\
\hline Underwater trauma & 44,45 & & 345 & & 45 \\
\hline $\begin{array}{l}\text { Single } \\
\text { prolonged stress }\end{array}$ & 53,324 & & 61,62 & & 54,286 \\
\hline $\begin{array}{l}\text { Social defeat stress } \\
\text { Resident-intruder } \\
\text { social defeat }\end{array}$ & 89,307 & 346 & 72 & 326 & 73,90 \\
\hline $\begin{array}{l}\text { Witnessed } \\
\text { social defeat }\end{array}$ & 313,328 & & 20,67 & & 74 \\
\hline $\begin{array}{l}\text { Cage-within-cage } \\
\text { resident-intruder } \\
\text { social defeat }\end{array}$ & 68 & & 242 & & \\
\hline $\begin{array}{l}\text { Predator stress } \\
\text { Predator } \\
\text { exposure stress }\end{array}$ & 96,97 & & 347 & & 96,99 \\
\hline $\begin{array}{l}\text { Predator-based } \\
\text { psychosocial stress }\end{array}$ & 101 & & 110 & & \\
\hline Predator scent stress & 129,130 & 118 & 348 & & 112,124 \\
\hline
\end{tabular}

\section{Non-standardized experimental designs}

Experimental designs are often not standardized across laboratories, complicating inter-laboratory comparison and result replication. Studies differ in their methods of trauma exposure, behavioral test batteries, and data analysis. This variability is exacerbated through differences in experimenter sex, rodent sex, species/strain/stock, age, housing and noise conditions (e.g., stressed and control animals caged separately/together, individually ventilated cages), food, incubation time between trauma and testing, acclimation time to the testing room and its light intensity, location of trauma and testing rooms, transportation to the testing room, subject location during trauma and testing of other subjects, specific tests conducted and their order, test duration, and test timing (light or dark cycle). All of these factors have a non-trivial effect on results and illustrate the often-underestimated importance of attention to detail.

\section{Insufficient reporting}

Many publications have insufficiently reported experimental details, rendering them not fit-for-purpose and limiting their value to researchers, doctors, and policymakers ${ }^{151}$. This challenge is compounded by concerns of positive publication bias, which favors the reporting of positive results (data supporting an alternative hypothesis) and can lead to spurious claims, wasteful experimentation, and reduced meta-analysis validity. Some journals (e.g., Journal of Negative Results in BioMedicine, Journal of Pharmaceutical Negative Results, Nature Negative Results section) compensate publication bias by exclusively publishing negative results. Favoring negative results, however, can also introduce bias ${ }^{152}$. Therefore, publishing criteria should focus on a study's design and statistical power, regardless of its outcome. Guidelines for planning and reporting animal experiments (e.g., Gold Standard Publication Checklist, Animal Research: Reporting of In Vivo Experiments, and Planning Research and Experimental Procedures on Animals: Recommendations for Excellence) have been established, but have not yet been widely adopted ${ }^{153-155}$. The lack of reproducibility in preclinical research may contribute to the failure of drugs in clinical trials ${ }^{156}$.

\section{Ethical complications}

Effective rodent models of PTSD utilize stressors that exceed the animal's homeostatic regulatory capacity, but 
ethical complications remain. Studies are expected to minimize rodent suffering, improve human health, and advance general scientific knowledge. Since exposure to a significant trauma is required, emphasizing reduction in animal distress is counterproductive in PTSD models. This may result in minimizing exposure type or severity such that the model's efficacy and scientific value is compromised $^{10,157}$. Predator scent stress, for example, developed in response to safeguards limiting predatorprey interactions, is less severe and may not as effectively induce the PTSD-like phenotype as predator exposure. Therefore, stressful experiences that are within a rodent's coping capacity should be distinguished from traumatic experiences that are beyond its coping capacity. Investigators are encouraged to collaborate with ethical committees to ensure that their selected exposure is relevant to PTSD and maximizes the probability of clinically significant findings.

\section{Future directions}

While it is apparent that well-established PTSD animal models are available, refining behavioral and neurobiological understanding of these models is still needed. Future directions include study of (1) individual variability and behavioral test batteries; (2) sex differences; (3) strain and stock differences; (4) early life stress effects; (5) biomarkers; as well as use of (6) stringent success criteria for drug development; (7) Research Domain Criteria (RDoC); (8) technological advances; and (9) cross-species comparisons.

\section{Individual variability and behavioral test batteries}

Many studies regard groups of animals under a condition as homogeneous, overlooking individual variability, and rely on a small number of tests with singular time points. Some models (e.g., immobilization stress, predator-based psychosocial stress) create a ubiquitous response in which all exposed animals present PTSD-like symptoms without the response variability inherent to human PTSD. Trends in variability have been described as "bidirectional" (Table 6), but with different meanings across research groups. Bidirectional expression has been used to mean both the concurrence or alternation between increased (i.e., intrusive re-experiencing, hyperarousal) and decreased (i.e., avoidance, numbing) responsiveness across different behavioral tests or subgroupings of animals within an experimental group. For example, a model could satisfy Yehuda and Antelman's bidirectional criterion by showing that a group of animals display hyperarousal in ASR and anhedonia in sucrose preference or that stressed subgroups show opposite responses to the same stimulus. When only a subgroup is expected to display long-term PTSD-like phenotypes, analyzing group level statistics based on exposed and control groups can lead to weaker statistical power and would make results harder to translate. While animal behavioral studies often employ few tests post-exposure to detect symptoms, test batteries covering multiple diagnostic criteria can achieve a more reliable profiling of individual animals. With multiple tests and time points, behavioral changes measured before and after stress could provide insight into the direct effects of stress over time, controlling for subject variability. Interpreting results in a manner similar to human diagnosis (e.g., cut-off behavioral criteria ${ }^{96}$, median split criteria ${ }^{119}$, behavioral profiling $^{48}$, or clustering methods) then allows for the classification of susceptible and resilient trauma-exposed individuals. By researchers considering individual variability, treatments can be evaluated on whether they decrease the proportion of maladapted animals instead of their effect on symptom severity.

\section{Sex differences}

Sex differences are another area of variability that has been poorly studied (Table 4). PTSD was introduced into the DSM-III following the high prevalence of male Vietnam veterans seeking treatment for posttrauma symptoms ${ }^{158}$. All psychiatric disorders display sex differences, yet male rodents have been predominantly studied given the historical perspective of past publications ${ }^{159}$. Overreliance on male animals and cells conceals sex differences and may contribute to the increase of nontranslationality in preclinical research ${ }^{156}$. Due to the push to address sex differences, in consideration of females' higher prevalence of PTSD and adverse drug reactions, preclinical studies are now studying sex differences more readily ${ }^{6,160}$. Noting discrepancies in diagnostic criteria between the DSM-IV, DSM-5, and 10th Revision of the International Classification of Diseases (ICD-10), studies suggest that sex differences in symptom endorsement may make females more likely to meet DSM-5 and ICD-10 criteria for PTSD. Females were more likely to endorse intrusive thoughts, avoidance of external reminders, emotional blunting, exaggerated startle response, and sleep disturbance, while males were more likely to endorse aggressive behavior symptoms ${ }^{161,162}$. Sex differences in coping strategies, possibly mediated by differential endocrine responses (e.g., cortisol and oxytocin), have also been proposed ${ }^{163}$. Furthermore, human and rodent findings have suggested that differences in interactions between gonadal hormones testosterone or estrogen with the HPA axis or hippocampus contribute to the increased disorder risk among females ${ }^{164-166}$. Evaluations of behavioral effects of estrous cycle phase in female rodents observed trait and strain differences in test performance stability across phases, concluding that choices of behavioral paradigms, testing conditions, and genetic backgrounds are critical to controlling for 
hormonal effects ${ }^{167}$. However, hormone variation should be monitored as it could confound data interpretation or behavioral phenotyping performed blind to estrous cycle phase. In addition, studies should be designed with an adequate sample size to homogenize the estrous phase distribution. Further research is needed to understand the effects of hormones on PTSD and to develop hormonesensitive treatments.

\section{Strain and stock differences}

Similar to humans, rodent genetic background modulates stress susceptibility and phenotype variation, yet strain and stock differences have not been sufficiently characterized. Inbred strains of mice (e.g., C57BL/6, $\mathrm{BALB} / \mathrm{c}$ ) and rats (e.g., Lewis, Fischer), genetically homogenous, are used to minimize intrastrain differences. In contrast, outbred stocks of mice (e.g., Swiss, CD-1) and rats (e.g., Long-Evans, Sprague-Dawley), genetically heterogenous, are used to model the variability of human populations. The $\mathrm{C} 57 \mathrm{Bl} / 6$ strain is reported to be more resilient to early life stress compared to strains such as the anxious BALB/c strain ${ }^{168,169}$. In addition, strain and stock differences in baseline behavior and psychotropic treatment response have been identified ${ }^{170,171}$. Therefore, rodent strain/stock, vendor, and colony should be considered across experiments within a study to better control experimental conditions and increase result reproducibility. Further research may reveal phenotypic behavioral differences with underlying genetic bases relevant to PTSD susceptibility.

\section{Early life stress effects}

Although early life stress, such as childhood abuse, increases vulnerability to psychiatric disorders later in life, this relationship is not clearly understood ${ }^{172}$. To better understand this relationship, early life stress is modeled in rodents through interventions in mother-pup interaction time periods (e.g., early handling for 3-15 min, repeated maternal separation for $1-8 \mathrm{~h}$, single maternal separation for $24 \mathrm{~h}$ ), the quantity and/or quality of maternal care (e.g., repeated cross-fostering, naturally occurring differences in maternal care, impoverished postnatal environment), and pharmacology (e.g., postnatal glucocorticoids, postnatal lipopolysaccharide) ${ }^{173,174}$. Since the brain's neurocircuitry matures from adolescence to early adulthood, trauma response may change over time ${ }^{175}$. In addition to effects of early life stress on brain and behavior over the developmental course, open research areas include identification of gene-environment interactions, epigenetic processes, sensitive periods, methods for disorder prevention or reversal, and beneficial effects. Different hypotheses exist to explain the interaction between early and adult stress in mental disorder susceptibility. Whereas multiple hit models, such as the cumulative- (diathesis-)stress hypothesis, state that disease risk increases with more adversity, the match/mismatch hypothesis states that risk deceases when early and adult environments match (stress inoculation), but increases upon mismatch ${ }^{176,177}$. Similarly, the differential susceptibility to environmental influence ("for-better-and-forworse") hypothesis states that individuals carrying alleles that are reactive to the environment display heightened sensitivity to disease risk in stressful contexts, but also to beneficial effects in supportive conditions ${ }^{178}$. Integrating hypotheses and considering individual differences in early programming sensitivity, the three-hit concept of vulnerability and resilience incorporates genetic predisposition, early life environment, and later life environment ${ }^{179,180}$. Additional assessments across the life span should be conducted to evaluate these hypotheses and clarify the relationship between maltreatment in early life and mental illness in adulthood.

\section{Biomarkers}

Potential PTSD biomarkers have been identified, but the topic remains underdeveloped as there are no biomarkers of susceptibility, disease, or therapy in clinical use. An individual's susceptibility to developing PTSD can be evaluated before trauma through risk markers for primary prevention, to prevent exposure, and early after trauma through risk markers for secondary prevention, to begin preventative therapy before symptom expression. Reported primary risk markers in humans include: (1) high fear response to a single $35 \% \mathrm{CO}_{2}$ inhalation challenge ${ }^{181}$; (2) gene $\times$ environment interactions (e.g., FK506 binding protein 5 (FKBP5) gene $\times$ childhood trauma) ${ }^{182}$; (3) HPAaxis regulators ${ }^{183}$; (4) frequent nightmares (possibly related to the hampered fear extinction memory consolidation associated with REM sleep) ${ }^{184}$; and (5) low hippocampal volume ${ }^{185}$. Few secondary risk markers, apart from increased heart rate ${ }^{186}$, have been reported because of sample size and prospective design limitations. Prominent disease diagnostic markers include HPA-axis dysregulation $^{187}$, FKBP5 expression ${ }^{188}$, sympathetic nervous system hyperreactivity ${ }^{189}$, low hippocampal volume $^{190}$, and high amygdala activity ${ }^{191}$. Use of biomarkers as inclusion or exclusion criteria for patient enrollment into clinical studies increases a drug candidate's likelihood of FDA approval ${ }^{192}$. However, few PTSD therapy stratification/selection markers, used to predict treatment responses and stratify patients by therapy responder types, or progress markers, used to monitor therapy responses, have been determined. The field's attempts to identify PTSD biomarkers has not resulted in treatments, so the aim that animal models will provide targets that will inform treatments has not yet been accomplished $^{142}$. This is because biomarkers are currently limited by their interdependence, contribution to other 
disorders, inconsistent effect distribution, and small effect ${ }^{146}$. It is, therefore, important to determine how to use animal models to successfully translate findings. With multimodal study designs, identification of biomarkers that are homologous across species and play similar roles in the model and clinical condition will compliment behavioral measures to inform clinical trials of diagnostic and treatment targets. For reviews of PTSD biomarkers, see DePierro and Schmidt ${ }^{142,193}$.

\section{Stringent success criteria}

Implementing stringent success criteria into the preclinical stage of testing may improve upon the traditional drug development approach of expediting treatments into clinical trials to collect human data as early as possible. The unmet need for PTSD treatments may have reduced regulatory restrictions to their development and allowed drugs with suboptimal preclinical validation to enter clinical trials. Consequently, central nervous system drug candidates now have the second lowest success rate among therapeutic areas and take longer to bring to market ${ }^{192,194}$. The majority of drugs that showed initial promise in animal models failed in phases II and III of clinical development due to a lack of efficacy ${ }^{195-198}$. For example, Bionomics' BNC210, a negative allosteric modulator of the $\alpha 7$ nicotinic acetylcholine receptor, failed to significantly improve symptoms compared to placebo in a Phase II PTSD trial because of insufficient exposure (bioavailability) ${ }^{199}$. Target site exposure, target binding, and expression of functional pharmacological activity (the "three pillars of survival") all determine the likelihood of candidate survival in Phase II and progression to Phase III trials ${ }^{200}$. This underscores the importance of acquiring preclinical pharmacokinetic and pharmacodynamic data to test drug mechanisms and success. In response to the high unsustainable cost of clinical trials, pharmaceutical companies, including Bionomics, have downscaled, outsourced, or closed their neuroscience research programs $^{201-203}$. The FDA estimates that a $10 \%$ improvement in failure prediction before clinical trials could save $\$ 100$ million in development costs per drug ${ }^{204}$. Stringent success criteria would improve failure prediction by requiring more preclinical validation, thus shifting risk from the clinical to the preclinical stage. This may then decrease drug development costs, times to market, and prices to the public ${ }^{151}$.

\section{Research domain criteria}

PTSD is a heterogeneous disorder and the field is shifting focus from generalized diagnostic criteria toward targeting specific symptom domains. In parallel to disease-specific DSM-5 criteria, the US National Institute of Mental Health's RDoC is a framework for subject characterization based on degrees of dysfunctions in psychological/biological systems. Therefore, the RDoC assumes that there is a dimensional continuum between health and pathology. The $\mathrm{RDoC}$ matrix consists of dimensional psychological constructs (or concepts), grouped into higher-level domains of human behavior and functioning, and distinguished by the units of analysis used to investigate constructs. Continuously evolving from more construct validity and utility data, the RDoC matrix currently has five domains (negative valence, positive valence, cognitive, social processes, arousal and regulatory systems) and eight units of analysis (genes, molecules, cells, circuits, physiology, behavior, self-report, paradigms) ${ }^{205}$. Additional domains that are relevant to PTSD and psychiatric research have been proposed, namely stress and emotional regulation and maintenance of consciousness ${ }^{206}$. Intended to inform future diagnostic systems, RDoC integrates multiple measures for a comprehensive understanding of matrix constructs and, consequently, their corresponding symptoms. Investigators should align studies to RDoC as it encourages scientists to seek beyond observable results to neurobiological measures. Using a more stringent criteria for what we consider as a rodent model based on the criteria discussed can improve the translatability of results.

\section{Technological advances}

Utilizing technological advances in neuroimaging and genetic manipulation in PTSD research is promising as it allows for longitudinal assessments and investigations of circuits governing PTSD etiology. In clinical practice, neuroimaging, specifically structural, is mostly used to exclude brain pathology from the cause of psychiatric symptoms. Since diagnosis is subjective, quantitative clinical measures are needed to validate the current qualitative criteria and give preclinical researchers confidence that they are modeling PTSD, rather than genetic variability. Recent technological advances may be employed to achieve this goal and improve information flow between the two fields. fMRI, for example, measures blood-oxygenation-level dependent signal as an indirect indicator of neuronal activity. It is a powerful noninvasive measure of systems-level brain function and has a higher spatial resolution than other noninvasive modalities such as electroencephalography. MRI has been used to demonstrate altered fractional anisotropy, focal neural activity, functional connectivity, as well as focal atrophy of gray matter ${ }^{207}$. Awake rat rsfMRI avoids confounding factors from anesthetics and can be correlated with behavioral measures to study functional networks implicated in stress response, discover new regions of interest, and define endophenotypes of susceptibility ${ }^{208}$. Since fMRI can be applied to both animals and humans, findings may be translated across species and the conservation of neural circuits may be compared ${ }^{209}$. Stress signaling 


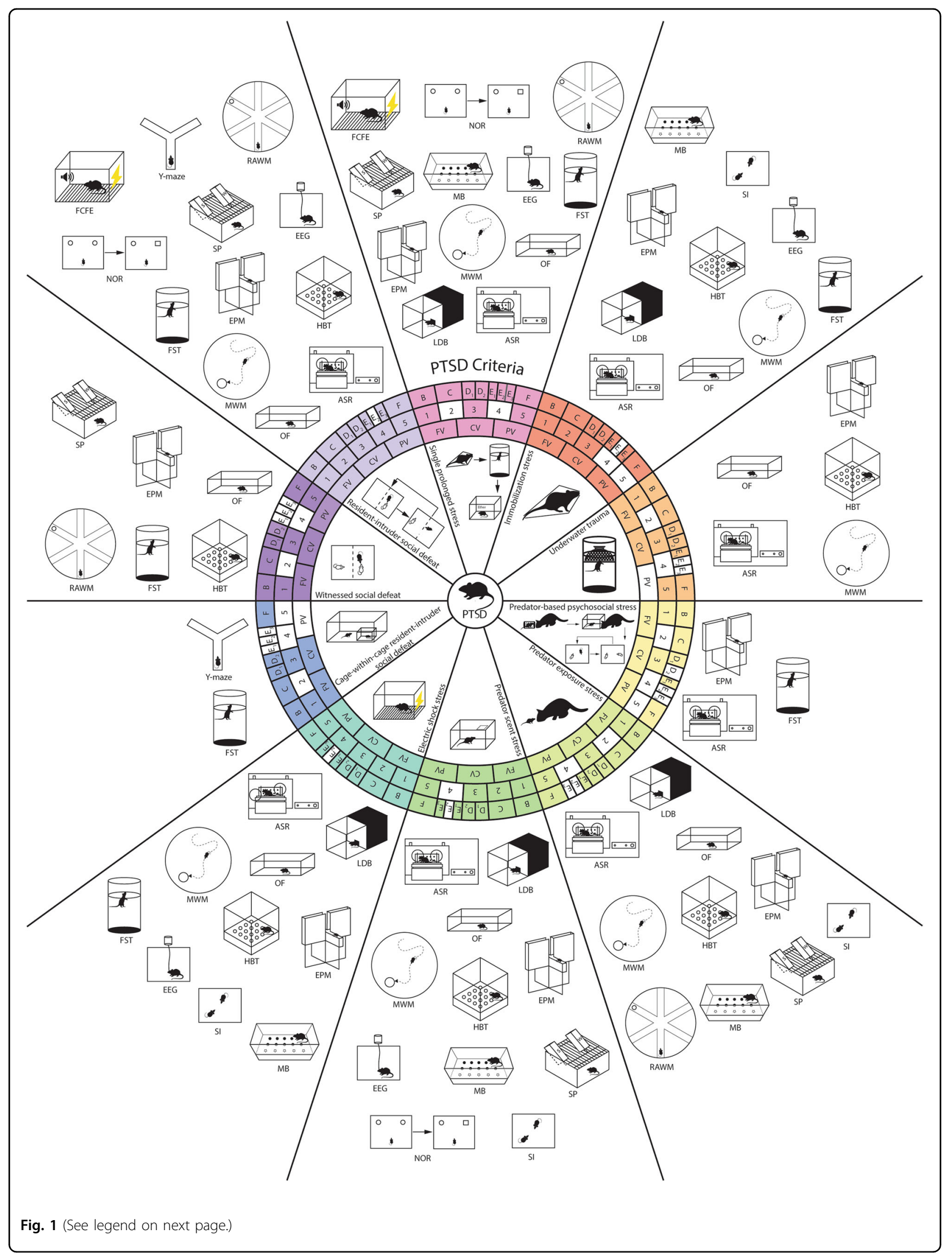


(see figure on previous page)

Fig. 1 Superimposition of reviewed animal models against validity criteria for animal models of human mental disorders (inner circle), Yehuda and Antelman's criteria for animal models of PTSD (middle circle), and DSM-5 criteria for PTSD (outer circle). Validity criteria abbreviations: face validity (FV), construct validity (CV), predictive validity (PV). Yehuda and Antelman's criteria abbreviations: biological and behavioral sequelae of PTSD (1), dose-dependent (2), lasting symptoms (3), bidirectional (4), interindividual variability (5). DSM-5 criteria abbreviations: physiological reactions to trauma reminders $(B)$, increased avoidance $(C)$, cognitive alterations $\left(D_{1}\right)$, mood alterations $\left(D_{2}\right)$, increased arousal $\left(E_{1}\right)$, concentration problems $\left(E_{2}\right)$, sleep disturbance $\left(E_{3}\right)$, lasting symptoms (F). Behavioral test abbreviations: elevated plus maze (EPM), open field (OF), light-dark box (LDB), Morris water maze (MWM), radial arm water maze (RAWM), fear conditioning / fear extinction (FCFE), novel object recognition (NOR), social interaction (SI), forced swim test (FST), sucrose preference (SP), marble burying (MB), acoustic startle response (ASR),

electroencephalogram (EEG). White: not reported. Shaded: reported.

pathways can also be selectively stimulated via optogenetics and chemogenetics (or pharmacogenetics). Optogenetics enables manipulation of neuronal activity in stress circuits through activation of light-sensitive proteins, such as microbial opsins, that are selectively inserted into intact living mammalian neurons. Using this technology, researchers can control cell firing patterns with high tissue specificity and temporal precision to study the causal relationship between circuits and behavior in PTSD ${ }^{210}$. In chemogenetics, instead of with light, cell populations and neural circuits are modulated by the injection of biologically inert ligands that activate engineered receptors. Designer Receptors Exclusively Activated by Designer Drugs are widely used in chemogenetics and act through G-protein coupled signaling cascades. Chemogenetics has a lower temporal resolution, but is relatively noninvasive compared to optogenetics, which requires fiber-optic implants ${ }^{211}$. Integrated with $\mathrm{fMRI}$, these technologies can map the downstream effects of local manipulations on global brain activity $^{212-214}$. The neurobiology of stress can also be studied through diffusion tensor imaging ${ }^{215}$, magnetoencephalography ${ }^{216}$, calcium-based fiber photometry $^{217,218}$, and molecular $\mathrm{fMRI}^{214}$. Combined with fMRI, these multimodal methods allow researchers to collect complementary and multi-dimensional information across spatiotemporal scales on the same animal. Implementation of these tools in studies of PTSD animal models and integration with established techniques in behavioral analysis, electrophysiology, and pharmacology can unveil progressive changes after stress exposure and susceptibility endophenotypes. While reliance on qualitative assessment is still standard, the shift towards multimodal methods will allow for the determination of quantitative PTSD biomarkers that are predictive of qualitative criteria used to assess PTSD prevalence. This goal will likely require increased collaboration between clinical and preclinical researchers to be achieved.

\section{Cross-species comparisons}

Cross-species comparisons of stress responses over the phylogenetic scale, ranging from rodents to animals in the genus Mustela (e.g., weasels, ferrets, minks) and nonhuman primates, are required to truly understand the preservation of PTSD features. Neurobiological results from rodent studies have already shown relevance in other species, but with mild stress models ${ }^{219,220}$. For example, both rodent and primate research has identified brain regions, such as the bed nucleus of the stria terminalis (BNST), amygdala, prefrontal cortex, cingulate cortex, and hippocampus, that regulate stress-related behavioral mechanisms and are dysfunctional in PTSD patients ${ }^{146}$. The BNST, in particular, has been investigated for its role in fear memory neural circuitry ${ }^{221}$. In mice, optogenetic photoinhibition of neurons projecting between the BNST and ventral tegmental area during electric shock stress decreased freezing in the exposure context and closed arm entries in the $\mathrm{EPM}^{222}$. Consequently, the BNST was investigated in rhesus monkeys and its intrinsic functional connectivity with the central nucleus of the amygdala was found to be correlated with behavioral responses to no-eye-contact human intruder stress $^{223}$. A possible translational roadmap for studying PTSD is to combine mechanistic and behavioral measures from rodents with multimodal neuroimaging measures from nonhuman primates and humans. Cross-species comparisons such as these show promise to elucidating the clinical relevance of stress-induced cellular, molecular, and microstructural discoveries in rodents.

\section{Conclusion}

Since a variety of traumas, producing specific symptoms, can trigger PTSD, a single rodent model will not perfectly capture a human individual's disorder complexity. While individual animal models can replicate lack of coping and ineffective adaptation to stress, this does not necessarily represent coverage of human PTSD variability. This shortcoming is in part rooted in the modeling of general trauma conditions such as life threats, while modeling effects of particular stimuli (e.g., burning odors, sounds of gunfire) or cognitive assessments (e.g., helplessness, self-blame, coping strategy) of the general trauma condition is not further explored. As studies of animal models continue to improve, incorporation of experimental designs that can highlight the effect of specific features of a trauma or drive specific 
coping strategies will improve animal models' representation of human PTSD variability. Similarly, more objective measures are needed to evaluate a rodent's inability to self-regulate, also a cognitive aspect of responses to anxiogenic stimuli, to assess aspects of human PTSD variability further in preclinical studies. This, along with the availability of physical, social, and psychological rodent stressors, varying in length and intensity, will improve translation of results to comparable clinical cases. Each model's strengths and limitations, reviewed here, should be considered for fit-for-purpose stress paradigm selection, hypothesis testing, and experimental design. For example, consideration of the DSM-5 risk and prognostic factors for PTSD in animal models (e.g., trauma reminders, female subjects, and early life stress) are likely to better replicate the human condition in patients with similar features. When evaluating paradigms, judging rodent models based on one set of criteria could be misleading because each focuses on different constructs. DSM- 5 criteria, designed to facilitate diagnosis of human mental disorders, are used to compare stressors by their representation of PTSD symptomatology. Expanding the comparison to etiology and treatment response, validity criteria are used for animal models of human mental disorders. Yehuda and Antelman's criteria, more specific, are used for animal models of PTSD and include factors that are essential to the induction of PTSD-like phenotypes. Therefore, all three criteria should be superimposed for the optimal reflection of a stressor's relevance to PTSD (Fig. 1). As only a minority of individuals who experience traumatic event(s) develop the disorder, it is important to investigate animals' individual variability in stress response and subsequent development of PTSD-like behaviors to distinguish susceptibility. It is also important to remember that the goal of this research is to expand knowledge and improve the clinical treatment of PTSD. Despite the large financial investment and the thousands of papers published annually, no treatments have been approved for PTSD since Paxil in 2000. With the incorporation of the directions discussed, rodent models of PTSD can provide more utility and translational impact as they lead to shifts in practice.

\section{Acknowledgements}

This study was partially supported by National Institute of Neurological Disorders and Stroke Grant R01NS085200 (PI: Nanyin Zhang, PhD) and National Institute of Mental Health Grant R01MH098003 and RF1MH114224 (PI: Nanyin Zhang, PhD).

\footnotetext{
Author details

'Department of Engineering Science and Mechanics, The Pennsylvania State University, University Park, PA 16802, USA. ${ }^{2}$ Department of Biomedical Engineering, The Pennsylvania State University, University Park, PA 16802, USA. ${ }^{3}$ The Huck Institutes of Life Sciences, The Pennsylvania State University, University Park, PA 16802, USA
}

Conflict of interest

The authors declare that they have no conflict of interest.

\section{Publisher's note}

Springer Nature remains neutral with regard to jurisdictional claims in published maps and institutional affiliations.

Received: 8 October 2019 Revised: 17 March 2020 Accepted: 8 April 2020 Published online: 06 May 2020

\section{References}

1. Koenen, K. C. et al. Posttraumatic stress disorder in the World Mental Health Surveys. Psychol. Med. 47, 2260-2274 (2017).

2. Kessler, R. C., Sonnega, A., Bromet, E., Hughes, M. \& Nelson, C. B. Posttraumatic stress disorder in the national comorbidity survey. JAMA Psychiatry $\mathbf{5 2}$ 1048-1060 (1995)

3. Pietrzak, R. H., Goldstein, R. B., Southwick, S. M. \& Grant, B. F. Prevalence and Axis I comorbidity of full and partial posttraumatic stress disorder in the United States: results from Wave 2 of the National Epidemiologic Survey on Alcohol and Related Conditions. J. Anxiety Disord. 25, 456-465 (2011).

4. Alegría, M. et al. Prevalence, risk, and correlates of posttraumatic stress disorder across ethnic and racial minority groups in the United States. Med. Care 51, 1114-1123 (2013).

5. Kessler, R. C. et al. Lifetime prevalence and age-of-onset distributions of DSMIV disorders in the national comorbidity survey replication. JAMA Psychiatry 62, 593-602 (2005).

6. American Psychiatric Association. Diagnostic and statistical manual of mental disorders: DSM-5 ${ }^{T M}$ 5th edn. (American Psychiatric Publishing, Inc., 2013).

7. Willner, P. Validation criteria for animal models of human mental disorders: learned helplessness as a paradigm case. Prog. Neuropsychopharmacol. Biol. Psychiatry 10,677-690 (1986).

8. Yehuda, R. \& Antelman, S. M. Criteria for rationally evaluating animal models of postraumatic stress disorder. Biol. Psychiatry 33, 479-486 (1993).

9. Deslauriers, J., Toth, M., Der-Avakian, A. \& Risbrough, V. B. Current status of animal models of posttraumatic stress disorder: behavioral and biological phenotypes, and future challenges in improving translation. Biol. Psychiatry 83, 895-907 (2018).

10. Richter-Levin, G., Stork, O. \& Schmidt, M. V. Animal models of PTSD: a challenge to be met. Mol. Psychiatry https://doi.org/10.1038/s41380-018-0272-5 (2018).

11. Borghans, B. Animal models for posttraumatic stress disorder: an overview of what is used in research. World J. Psychiatry https://doi.org/10.5498/wjp.v5. i4.387 (2015)

12. Török, B., Sipos, E., Pivac, N. \& Zelena, D. Modelling posttraumatic stress disorders in animals. Prog. Neuro-Psychopharmacol. Biol. Psychiatry 90, 117-133 (2019).

13. Zhang, L. et al. Updates in PTSD Animal Models Characterization. In Psychiatric Disorders: Methods and Protocols (ed. Kobeissy, F. H.) 331-344 (Springer New York, 2019).

14. Flandreau, E. I. \& Toth, M. Animal Models of PTSD: A Critical Review. 1-22 (Springer Berlin Heidelberg, 2017).

15. Cohen, H., Matar, M. A. \& Zohar, J. Maintaining the clinical relevance of animal models in translational studies of post-traumatic stress disorder. ILAR J. $\mathbf{5 5}$ 233-245 (2014).

16. Semple, B. D., Blomgren, K., Gimlin, K. Ferriero, D. M. \& Noble-Haeusslein, L. J. Brain development in rodents and humans: Identifying benchmarks of maturation and vulnerability to injury across species. Prog. Neurobiol. 106-107, 1-16 (2013).

17. Clancy, B., Finlay, B. L., Darlington, R. B. \& Anand, K. J. S. Extrapolating brain development from experimental species to humans. Neurotoxicology $\mathbf{2 8}$ 931-937 (2007).

18. Paxinos, G. \& Franklin, K. B. J. Paxinos and Franklin's the Mouse Brain in Stereotaxic Coordinates (Academic Press, 2001).

19. Kalueff, A. V., Wheaton, M. \& Murphy, D. L. What's wrong with my mouse model?: advances and strategies in animal modeling of anxiety and depression. Behav. Brain Res. 179, 1-18 (2007).

20. Finnell, J. E. et al. Physical versus psychological social stress in male rats reveals distinct cardiovascular, inflammatory and behavioral consequences PLoS ONE 12, https://doi.org/10.1371/journal.pone.0172868 (2017). 
21. Seligman, M. E. P. Learned helplessness. Annu. Reviiew Med. 23, 407-412 (1972)

22. Aliczki, M. \& Haller, J. Electric shock as model of post-traumatic stress disorder in rodents. In Comprehensive Guide to Post-Traumatic Stress Disorder (eds. Martin, C. R., Preedy, V. R. \& Patel, V. B.) 1-16 (Springer International Publishing, 2014).

23. Rau, V., DeCola, J. P. \& Fanselow, M. S. Stress-induced enhancement of fear learning: an animal model of posttraumatic stress disorder. Neurosci. Biobehav. Rev. https://doi.org/10.1016/j.neubiorev.2005.04.010 (2005).

24. Rau, V. \& Fanselow, M. S. Exposure to a stressor produces a long lasting enhancement of fear learning in rats. Stress https://doi.org/10.1080/ 10253890802137320 (2009).

25. Pynoos, R. S., Ritzmann, R. F., Steinberg, A. M., Goenjian, A. \& Prisecaru, I. A behavioral animal model of posttraumatic stress disorder featuring repeated exposure to situational reminders. Biol. Psychiatry 39, 129-134 (1996).

26. Diehl, L. A. et al. Long lasting sex-specific effects upon behavior and S100b levels after maternal separation and exposure to a model of post-traumatic stress disorder in rats. Brain Res. https://doi.org/10.1016/j.brainres.2007.01.084 (2007)

27. Corral-Frias, N. S., Lahood, R. P., Edelman-Vogelsang, K. E., French, E. D. \& Fellous, J. M. Involvement of the ventral tegmental area in a rodent model of post-traumatic stress disorder. Neuropsychopharmacology https://doi.org/ 10.1038/npp.2012.189 (2013).

28. Siegmund, A. \& Wotjak, C. T. A mouse model of posttraumatic stress disorder that distinguishes between conditioned and sensitised fear. J. Psychiatr. Res. 41, 848-860 (2007).

29. Bali, A. \& Jaggi, A. S. Electric foot shock stress: a useful tool in neuropsychiatric studies. Rev. Neurosci. https://doi.org/10.1515/revneuro-2015-0015 (2015).

30. Gameiro, G. H. et al. Nociception- and anxiety-like behavior in rats submitted to different periods of restraint stress. Physiol. Behav. https://doi.org/10.1016/j. physbeh.2005.12.007 (2006).

31. Mitra, R., Jadhav, S., McEwen, B. S., Vyas, A. \& Chattarji, S. Stress duration modulates the spatiotemporal patterns of spine formation in the basolateral amygdala. Proc. Natl Acad. Sci. USA 102, $9371-9376$ (2005).

32. Kedia, S. \& Chattarji, S. Marble burying as a test of the delayed anxiogenic effects of acute immobilisation stress in mice. J. Neurosci. Methods https://doi. org/10.1016/j.jneumeth.2014.06.012 (2014).

33. Hegde, P. et al. Stress-induced changes in sleep and associated neuronal activity in rat hippocampus and amygdala. Neuroscience $\mathbf{1 5 3}$ 20-30 (2008)

34. Andero, R. et al. Amygdala-dependent fear is regulated by Oprl1 in mice and humans with PTSD. Sci. Transl. Med. https://doi.org/10.1126/scitranslmed. 3005656 (2013).

35. Armario, A., Valles, A., Dal-Zotto, S., Marquez, C. \& Belda, X. A single exposure to severe stressors causes long-term desensitization of the physiological response to homotopic stressor. Stress 7, 157 (2004).

36. Sahin, Z. et al. [An evaluation of the effects of two chronic immobilization stress protocols On depression/anxiety-related behavior in male rats]. Aclbadem Üniversitesi Sağlık Bilim. Derg. 10, https://doi.org/10.31067/0.2019.186 (2019).

37. Bali, A. \& Jaggi, A. S. Preclinical experimental stress studies: protocols, assessment and comparison. Eur. J. Pharmacol. 746, 282-292 (2015).

38. Fuentes, S. et al. Sex-dependent impact of early-life stress and adult immobilization in the attribution of incentive salience in rats. PLOS ONE https://doi.org/10.1371/journal.pone.0190044 (2018).

39. Yehuda, R., Yang, R. K., Buchsbaum, M. S. \& Golier, J. A. Alterations in cortisol negative feedback inhibition as examined using the $A C T H$ response to cortisol administration in PTSD. Psychoneuroendocrinology https://doi.org/ 10.1016/j.psyneuen.2005.10.007 (2006).

40. Zaba, M. et al. Identification and characterization of HPA-axis reactivity endophenotypes in a cohort of female PTSD patients. Psychoneuroendocrinology 55, 102-115 (2015).

41. Gagliano, H., Nadal, R. \& Armario, A. Sex differences in the long-lasting effects of a single exposure to immobilization stress in rats. Horm. Behav. 66 793-801 (2014).

42. Buynitsky, T. \& Mostofsky, D. I. Restraint stress in biobehavioral research: Recent developments. Neuroscience and Biobehavioral Reviews https://doi. org/10.1016/j.neubiorev.2009.05.004 (2009).

43. Moore, N. L. T., Gauchan, S. \& Genovese, R. F. Differential severity of anxiogenic effects resulting from a brief swim or underwater trauma in adolescent male rats. Pharmacol. Biochem. Behav. 102, 264-268 (2012).
44. Richter-Levin, G. Acute and long-term behavioral correlates of underwater trauma-potential relevance to stress and post-stress syndromes. Psychiatry Res. 79, 73-83 (1998)

45. Cohen, $\mathrm{H}$. et al. Setting apart the affected: the use of behavioral criteria in animal models of post traumatic stress disorder. Neuropsychopharmacology 29, 1962-1970 (2004).

46. Yehuda, R., McFarlane, A. \& Shalev, A. Predicting the development of posttraumatic stress disorder from the acute response to a traumatic event. Biol. Psychiatry 44, 1305-1313 (1998).

47. Sandi, C. \& Richter-Levin, G. From high anxiety trait to depression: a neurocognitive hypothesis. Trends Neurosci. https://doi.org/10.1016/j. tins.2009.02.004 (2009).

48. Ritov, G., Boltyansky, B. \& Richter-Levin, G. A novel approach to PTSD modeling in rats reveals alternating patterns of limbic activity in different types of stress reaction. Mol. Psychiatry 21, 630-641 (2016).

49. Harvey, B. H., Naciti, C., Brand, L. \& Stein, D. J. Endocrine, cognitive and hippocampal/cortical 5HT1A/2Areceptor changes evoked by a timedependent sensitisation (TDS) stress model in rats. Brain Res. https://doi. org/10.1016/S0006-8993(03)03033-6 (2003).

50. Liberzon, I., Krstov, M. \& Young, E. A. Stress-restress: effects on ACTH and fast feedback. Psychoneuroendocrinology 22, 443-453 (1997)

51. Zheng, S., Han, F., Shi, Y., Wen, L. \& Han, D. Single-prolonged-stress induced changes in autophagy-related proteins beclin-1, LC3, and p62 in the media prefrontal cortex of rats with post-traumatic stress disorder. J. Mol. Neurosci. 62, 43-54 (2017)

52. Knox, D. et al. Single prolonged stress disrupts retention of extinguished fear in rats. Learn. Mem. 19, 43-49 (2012).

53. Imanaka, A., Morinobu, S., Toki, S. \& Yamawaki, S. Importance of early environment in the development of post-traumatic stress disorder-like behaviors. Behav. Brain Res. https://doi.org/10.1016/j.bbr.2006.06.012 (2006).

54. Liu, H., Atrooz, F., Salvi, A. \& Salim, S. Behavioral and cognitive impact of early life stress: Insights from an animal model. Prog. Neuro-Psychopharmacology. Biol. Psychiatry 78, 88-95 (2017)

55. Keller, S. M., Schreiber, W. B., Staib, J. M. \& Knox, D. Sex differences in the single prolonged stress model. Behav. Brain Res. https://doi.org/10.1016/j. bbr.2015.02.034 (2015).

56. Zer-Aviv, T. M. \& Akirav, I. Sex differences in hippocampal response to endocannabinoids after exposure to severe stress. Hippocampus https://doi. org/10.1002/hipo.22577 (2016).

57. Gruene, T. M., Flick, K., Stefano, A., Shea, S. D. \& Shansky, R. M. Sexually divergent expression of active and passive conditioned fear responses in rats. Elife https://doi.org/10.7554/eLife.11352.001 (2015)

58. Pooley, A. E. et al. Sex differences in the traumatic stress response: The role of adult gonadal hormones. Biol. Sex Differ. https://doi.org/10.1186/s13293-0180192-8 (2018)

59. Pooley, A. E. et al. Sex differences in the traumatic stress response: PTSD symptoms in women recapitulated in female rats. Biol. Sex Differ. https://doi. org/10.1186/s13293-018-0191-9 (2018).

60. Yamamoto, S. et al. Single prolonged stress: Toward an animal model of posttraumatic stress disorder. Depression and Anxiety https://doi.org/10.1002/ da.20629 (2009).

61. Souza, R. R., Noble, L. J. \& McIntyre, C. K. Using the single prolonged stress model to examine the pathophysiology of PTSD. Front. Pharmacol. https:// doi.org/10.3389/fphar.2017.00615 (2017).

62. Lisieski, M. J., Eagle, A. L., Conti, A. C., Liberzon, I. \& Perrine, S. A. Singleprolonged stress: a review of two decades of progress in a rodent model of post-traumatic stress disorder. Front. Psychiatry 9, https://doi.org/10.3389/ fpsyt.2018.00196 (2018).

63. Daskalakis, N. P. \& Yehuda, R. Principles for developing animal models of military PTSD. Eur. J. Psychotraumatol. 5, https://doi.org/10.3402/ejpt.v5.23825 (2014).

64. Krishnan, V. \& Nestler, E. J. Animal models of depression: molecular perspectives. In Current Topics in Behavioral Neurosciences. Vol. 7, 121-147 (Springer-Verlag Berlin, 2011).

65. Golden, S. A., Covington, H. E., Berton, O. \& Russo, S. J. A standardized protocol for repeated social defeat stress in mice. Nat. Protoc. 6, 1183-1191 (2011).

66. Koolhaas, J. M. et al. The resident-intruder paradigm: a standardized test for aggression, violence and social stress. J. Vis. Exp. 77, e4367 (2013). 
67. Warren, B. L. et al. Neurobiological sequelae of witnessing stressful events in adult mice. Biol. Psychiatry 73, 7-14 (2013).

68. Hammamieh, R. et al. Murine model of repeated exposures to conspecific trained aggressors simulates features of post-traumatic stress disorder. Behav. Brain Res. 235, 55-66 (2012).

69. Albert, D. J., Dyson, E. M., Walsh, M. L. \& Petrovic, D. M. Cohabitation with a female activates testosterone-dependent social aggression in male rats independently of changes in serum testosterone concentration. Physiol. Behav. https://doi.org/10.1016/0031-9384(88)90054-6 (1988).

70. Clipperton Allen, A. E., Cragg, C. L., Wood, A. J., Pfaff, D. W. \& Choleris, E. Agonistic behavior in males and females: Effects of an estrogen receptor beta agonist in gonadectomized and gonadally intact mice. Psychoneuroendocrinology 35, 1008-1022 (2010).

71. Jacobson-Pick, S., Audet, M. C., McQuaid, R. J., Kalvapalle, R. \& Anisman, H. Social agonistic distress in male and female mice: changes of behavior and brain monoamine functioning in relation to acute and chronic challenges. PLOS ONE https://doi.org/10.1371/journal.pone.0060133 (2013).

72. Krishnan, V. et al. Molecular adaptations underlying susceptibility and resistance to social defeat in brain reward regions. Cell 131, 391-404 (2007).

73. Larrieu, T. et al. Hierarchical status predicts behavioral vulnerability and nucleus accumbens metabolic profile following Chronic social defeat stress. Curr. Biol. 27, 2202-2210.e4 (2017).

74. Hodes, G. E. et al. Individual differences in the peripheral immune system promote resilience versus susceptibility to social stress. Proc. Natl Acad. Sci. USA 111, 16136-16141 (2014).

75. Wang, H., Lee, I. S., Braun, C. \& Enck, P. Effect of probiotics on central nervous system functions in animals and humans: A systematic review. J. Neurogastroenterol. Motil. 22, 589-605 (2016).

76. Lehmann, M. L. \& Herkenham, M. Environmental enrichment confers stress resiliency to social defeat through an infralimbic cortex-dependent neuroanatomical pathway. J. Neurosci. https://doi.org/10.1523/jneurosci.057711.2011 (2011)

77. Covington, H. E. et al. Antidepressant effect of optogenetic stimulation of the medial prefrontal cortex. J. Neurosci. https://doi.org/10.1523/JNEUROSCl.173110.2010 (2010)

78. Chaudhury, D. et al. Rapid regulation of depression-related behaviours by control of midbrain dopamine neurons. Nature https://doi.org/10.1038/ nature11713 (2013)

79. Wook Koo, J. et al. Essential role of mesolimbic brain-derived neurotrophic factor in chronic social stress-induced depressive behaviors. Biol. Psychiatry https://doi.org/10.1016/j.biopsych.2015.12.009 (2016).

80. Francis, T. C. et al. Nucleus accumbens medium spiny neuron subtypes mediate depression-related outcomes to social defeat stress. Biol. Psychiatry https://doi.org/10.1016/j.biopsych.2014.07.021 (2015).

81. Challis, C., Beck, S. G. \& Berton, O. Optogenetic modulation of descending prefrontocortical inputs to the dorsal raphe bidirectionally bias socioaffective choices after social defeat. Front. Behav. Neurosci. https://doi.org/10.3389/ fnbeh.2014.00043 (2014).

82. Bosch, O. J. Maternal aggression in rodents: brain oxytocin and vasopressin mediate pup defence. Philos. Trans. Royal Soc. B https://doi.org/10.1098/ rstb.2013.0085 (2013).

83. Payne, A. P. \& Swanson, H. H. Agonistic behaviour between pairs of hamsters of the same and opposite sex in a neutral observation Area. Behaviour https://doi.org/10.1163/156853970X00402 (1970).

84. Davis, E. S. \& Marler, C. A. c-fos changes following an aggressive encounter in female California mice: a synthesis of behavior, hormone changes and neural activity. N Neuroscience https://doi.org/10.1016/..neuroscience.2004.05.034 (2004).

85. Haller, J., Fuchs, E., Halász, J. \& Makara, G. B. Defeat is a major stressor in males while social instability is stressful mainly in females: towards the development of a social stress model in female rats. Brain Res. Bull. https://doi.org/ 10.1016/S0361-9230(99)00087-8 (1999).

86. Bronson, F. H. \& Desjardins, C. Aggression in adult mice: modification by neonatal injections of gonadal hormones. Science (80-). https://doi.org/ 10.1126/science.161.3842.705 (1968).

87. Simon, N. G. \& Masters, D. B. Activation of male-typical aggression by testosterone but not its metabolites in C57BL/6J female mice. Physiol. Behav. 41, 405-407 (1987).

88. Whalen, R. E. \& Johnson, F. Aggression in adult female mice: chronic testosterone treatment induces attack against olfactory bulbectomized male and lactating female mice. Physiol. Behav. https://doi.org/10.1016/0031-9384 (88)90092-3 (1988).

89. Harris, A. Z. et al. A Novel method for chronic social defeat stress in female mice. Neuropsychopharmacology https://doi.org/10.1038/npp.2017.259 (2017).

90. Takahashi, A. et al. Establishment of a repeated social defeat stress model in female mice. Sci. Rep. 7, 12838 (2017).

91. Hammels, C. et al. Defeat stress in rodents: from behavior to molecules. Neurosci. Biobehav. Rev. https://doi.org/10.1016/..neubiorev.2015.10.006 (2015).

92. Adamec, R. E. \& Shallow, T. Lasting effects on rodent anxiety of a single exposure to a cat. Physiol. Behav. 54, 101-109 (1993).

93. Zoladz, P. R. et al. Differential expression of molecular markers of synaptic plasticity in the hippocampus, prefrontal cortex, and amygdala in response to spatial learning, predator exposure, and stress-induced amnesia. Hippocampus 22, 577-589 (2012).

94. Bakshi, V. P., Alsene, K. M., Roseboom, P. H. \& Connors, E. E. Enduring sensorimotor gating abnormalities following predator exposure or corticotropinreleasing factor in rats: A model for PTSD-like information-processing deficits? Neuropharmacology 62, 737-748 (2012).

95. Toth, $\mathrm{M}$. et al. Overexpression of forebrain $\mathrm{CRH}$ during early life increases trauma susceptibility in adulthood. Neuropsychopharmacology 41, 1681-1690 (2016).

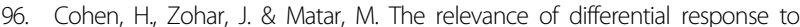
trauma in an animal model of posttraumatic stress disorder. Biol. Psychiatry 53, 463-473 (2003).

97. Adamec, R., Head, D., Blundell, J., Burton, P. \& Berton, O. Lasting anxiogenic effects of feline predator stress in mice: Sex differences in vulnerability to stress and predicting severity of anxiogenic response from the stress experience. Physiol. Behav. 88, 12-29 (2006).

98. Adamec, R., Hebert, M., Blundell, J. \& Mervis, R. F. Dendritic morphology of amygdala and hippocampal neurons in more and less predator stress responsive rats and more and less spontaneously anxious handled controls. Behav. Brain Res. 226, 133-146 (2012).

99. Mitra, R., Adamec, R. \& Sapolsky, R. Resilience against predator stress and dendritic morphology of amygdala neurons. Behav. Brain Res. 205, 535-543 (2009).

100. Apfelbach, R., Blanchard, C. D., Blanchard, R. J., Hayes, R. A. \& McGregor, I. S. The effects of predator odors in mammalian prey species: a review of field and laboratory studies. Neurosci. Biobehav. Rev. https://doi.org/10.1016/j. neubiorev.2005.05.005 (2005).

101. Zoladz, P. R., Conrad, C. D., Fleshner, M. \& Diamond, D. M. Acute episodes of predator exposure in conjunction with chronic social instability as an anima model of post-traumatic stress disorder. Stress 11, 259-281 (2008).

102. Zoladz, P. R., Fleshner, M. \& Diamond, D. M. Psychosocial animal model of PTSD produces a long-lasting traumatic memory, an increase in general anxiety and PTSD-like glucocorticoid abnormalities. Psychoneuroendocrinology 37, 1531-1545 (2012).

103. O'Doherty, D. C. M., Chitty, K. M., Saddiqui, S., Bennett, M. R. \& Lagopoulos, J. A systematic review and meta-analysis of magnetic resonance imaging measurement of structural volumes in posttraumatic stress disorder. Psychiatry Res. 232, 1-33 (2015)

104. Zoladz, P. R., Park, C. R., Fleshner, M. \& Diamond, D. M. Psychosocial predatorbased animal model of PTSD produces physiological and behaviora sequelae and a traumatic memory four months following stress onset. Physiol. Behav. 147, 183-192 (2015).

105. Wilson, C. B., Ebenezer, P. J., McLaughlin, L. D. \& Francis, J. Predator exposure/ psychosocial stress animal model of post-traumatic stress disorder modulates neurotransmitters in the rat hippocampus and prefrontal cortex. PLOS ONE $\mathbf{9}$, e89104 (2014)

106. Geracioti, T. D. et al. CSF norepinephrine concentrations in posttraumatic stress disorder. Am. J. Psychiatry 158, 1227-1230 (2001).

107. Geracioti, T. D. et al. Effect of traumatic imagery on cerebrospinal fluid dopamine and serotonin metabolites in posttraumatic stress disorder. J. Psychiatr. Res. 47, 995-998 (2013).

108. Zoladz, P. R. et al. A predator-based psychosocial stress animal model of PTSD in females: Influence of estrous phase and ovarian hormones. Horm. Behav. 115, 104564 (2019).

109. Rorabaugh, B. R. et al. Sex-dependent effects of chronic psychosocial stress on myocardial sensitivity to ischemic injury. Stress 18, 645-653 (2015). 
110. Zoladz, P. R. \& Diamond, D. M. Predator-based psychosocial stress animal model of PTSD: preclinical assessment of traumatic stress at cognitive, hormonal, pharmacological, cardiovascular and epigenetic levels of analysis. Exp. Neurol. 284, 211-219 (2016)

111. Itoga, C. A. et al. Traumatic stress promotes hyperalgesia via corticotropinreleasing factor-1 receptor (CRFR1) signaling in central amygdala. Neuropsychopharmacology 41, 2463-2472 (2016).

112. Cohen, $\mathrm{H}$. et al. Blunted HPA axis response to stress influences susceptibility to posttraumatic stress response in rats. Biol. Psychiatry 59, 1208-1218 (2006).

113. Liang, Z., King, J. \& Zhang, N. Neuroplasticity to a single-episode traumatic stress revealed by resting-state fMRI in awake rats. Neuroimage 103, 485-491 (2014).

114. Masini, C. V., Sauer, S., White, J., Day, H. E. W. \& Campeau, S. Non-associative defensive responses of rats to ferret odor. Physiol. Behav. 87, 72-81 (2006).

115. Morrow, B. A., Roth, R. H. \& Elsworth, J. D. TMT, a predator odor, elevates mesoprefrontal dopamine metabolic activity and disrupts short-term working memory in the rat. Brain Res. Bull. 52, 519-523 (2000).

116. Zangrossi, H. \& File, S. E. Behavioral consequences in animal tests of anxiety and exploration of exposure to cat odor. Brain Res. Bull. 29, 381-388 (1992).

117. Wallace, K. J. \& Rosen, J. B. Predator odor as an unconditioned fear stimulus in rats: elicitation of freezing by trimethylthiazoline, a component of fox feces. Behav. Neurosci. https://doi.org/10.1037/0735-7044.114.5.912 (2000).

118. Takahashi, L. K., Nakashima, B. R., Hong, H. \& Watanabe, K. The smell of danger: a behavioral and neural analysis of predator odor-induced fear. Neurosci. Biobehav. Rev. 29, 1157-1167 (2005)

119. Schwendt, M. et al. A novel rat model of comorbid PTSD and addiction reveals intersections between stress susceptibility and enhanced cocaine seeking with a role for mGlu5 receptors. Transl. Psychiatry 8, 209 (2018).

120. Mazor, A. et al. Gender-related qualitative differences in baseline and post-stress anxiety responses are not reflected in the incidence of criterion-based PTSD-like behaviour patterns. World J. Biol. Psychiatry 10, 856-869 (2009).

121. Koresh, O. et al. Distinctive cardiac autonomic dysfunction following stress exposure in both sexes in an animal model of PTSD. Behav. Brain Res. 308, 128-142 (2016).

122. Cohen, $\mathrm{H}$. et al. Long-lasting behavioral effects of juvenile trauma in an animal model of PTSD associated with a failure of the autonomic nervous system to recover. Eur. Neuropsychopharmacol. 17, 464-477 (2007).

123. Danan, D., Matar, M. A., Kaplan, Z., Zohar, J. \& Cohen, H. Blunted basal corticosterone pulsatility predicts post-exposure susceptibility to PTSD phenotype in rats. Psychoneuroendocrinology 87, 35-42 (2018)

124. Dopfel, D. et al. Individual variability in behavior and functional networks predicts vulnerability using an animal model of PTSD. Nat. Commun. 10, 2372 (2019).

125. Zohar, J. et al. High dose hydrocortisone immediately after trauma may alter the trajectory of PTSD: Interplay between clinical and animal studies. Eur. Neuropsychopharmacol. 21, 796-809 (2011).

126. Cohen, S. et al. Post-exposure sleep deprivation facilitates correctly timed interactions between glucocorticoid and adrenergic systems, which attenuate traumatic stress responses. Neuropsychopharmacology https://doi. org/10.1038/npp.2012.94 (2012).

127. Cohen, S., Kaplan, Z., Zohar, J. \& Cohen, H. Preventing sleep on the first resting phase following a traumatic event attenuates anxiety-related responses. Behav. Brain Res. https://doi.org/10.1016/j.bbr.2016.10.039 (2017).

128. LeDoux, J. Rethinking the emotional brain. Neuron 73, 653-676 (2012).

129. Cohen, H., Kozlovsky, N., Alona, C., Matar, M. A. \& Joseph, Z. Animal model for PTSD: From clinical concept to translational research. Neuropharmacology 62 715-724 (2012).

130. Staples, L. G. Predator odor avoidance as a rodent model of anxiety: Learning-mediated consequences beyond the initial exposure. Neurobiol. Learn. Mem. 94, 435-445 (2010).

131. Cryan, J. F. \& Holmes, A. The ascent of mouse: advances in modelling human depression and anxiety. Nat. Rev. Drug Discov. 4, 775-790 (2005).

132. Bourin, M., Petit-Demoulière, B., Nic Dhonnchadha, B. \& Hascöet, M. Animal models of anxiety in mice. Fundam. Clin. Pharmacol. 21, 567-574 (2007).

133. Berridge, K. C. Measuring hedonic impact in animals and infants: microstructure of affective taste reactivity patterns. Neurosci. Biobehav. Rev. https:// doi.org/10.1016/S0149-7634(99)00072-X (2000).

134. Knutson, B., Burgdorf, J. \& Panksepp, J. Ultrasonic vocalizations as indices of affective states in rats. Psychol. Bull. https://doi.org/10.1037/ 0033-2909.128.6.961 (2002).
135. Bushnell, P. J. \& Strupp, B. J. Assessing attention in rodents. In Methods of Behavior Analysis in Neuroscience (CRC Press/Taylor \& Francis, 2009).

136. Garattini, S. Are me-too drugs justified? J. Nephrol 10, 283-294 (1997).

137. Brady, K. et al. Efficacy and safety of sertraline treatment of posttraumatic stress disorder: a randomized controlled trial. JAMA 283, 1837-1844 (2000).

138. Marshall, R. D., Beebe, K. L., Oldham, M. \& Zaninelli, R. Efficacy and safety of paroxetine treatment for chronic PTSD: a fixed-dose, placebo-controlled study. Am. J. Psychiatry https://doi.org/10.1176/appi.ajp.158.12.1982 (2001).

139. VAVDoD Management of Post-Traumatic Stress Working Group. VA / DoD Clinical Practice Guideline For The Management Of Posttraumatic Stress Disorder and Acute Stress Disorder. Department of Veterans Affairs Department of Defense https://doi.org/10.1016/j.addbeh.2017.07.010 (2016).

140. American Psychological Association. Clinical Practice Guideline for the Treatment of Posttraumatic Stress Disorder (PTSD). (APA, Guideline Development Panel for the Treatment of Posttraumatic Stress Disorder in Adults, Washington, DC, 2017).

141. NICE. Post-traumatic stress disorder: management. National Institute for Health and Care Excellence (2018).

142. DePierro, J., Lepow, L., Feder, A. \& Yehuda, R. Translating molecular and neuroendocrine findings in posttraumatic stress disorder and resilience to novel therapies. Biol. Psychiatry 86, 454-463 (2019).

143. Mushtaq, D., Ali, A., Margoob, M. A., Murtaza, I. \& Andrade, C. Association between serotonin transporter gene promoter-region polymorphism and 4 and 12-week treatment response to sertraline in posttraumatic stress disorder. J. Affect. Disord. https://doi.org/10.1016/j.jad.2011.08.033 (2012).

144. Guo, W. et al. Exploratory genome-wide association analysis of response to ketamine and a polygenic analysis of response to scopolamine in depression. Transl. Psychiatry 8, 280 (2018).

145. Siegmund, A. \& Wotjak, C. T. Toward an animal model of posttraumatic stress disorder. Ann. NY Acad. Sci. 1071, 324-334 (2006).

146. Shalev, A., Liberzon, I. \& Marmar, C. Post-traumatic stress disorder. N. Engl. J. Med. 376, 2459-2469 (2017).

147. Singewald, N. \& Holmes, A. Rodent models of impaired fear extinction. Psychopharmacology 236, 21-32 (2019).

148. LeDoux, J. E. Semantics, surplus meaning, and the science of fear. Trends Cogn. Sci. 21, 303-306 (2017).

149. Holmes, P. Rodent models of depression: reexamining validity without anthropomorphic inference. Crit. Rev. Neurobiol. 15, 143-174 (2003).

150. Fadok, J. P. et al. A competitive inhibitory circuit for selection of active and passive fear responses. Nature 542, 96-100 (2017).

151. Denayer, T., Stöhr, T. \& Van Roy, M. Animal models in translational medicine: validation and prediction. N. Horiz. Transl. Med. 2, 5-11 (2014).

152. Mlinarić, A., Horvat, M. \& Šupak Smolčić, V. Dealing with the positive publication bias: why you should really publish your negative results. Biochem. Med. 27, 30201 (2017).

153. Smith, A. J., Clutton, R. E., Lilley, E., Hansen, K. E. A. \& Brattelid, T. PREPARE: guidelines for planning animal research and testing. Lab. Anim. 52, 135-141 (2017).

154. Kilkenny, C., Browne, W. J., Cuthill, I. C., Emerson, M. \& Altman, D. G. Improving bioscience research reporting: the ARRIVE guidelines for reporting animal research. PLOS Biol. 8, e1000412 (2010).

155. Hooijmans, C. R., Leenaars, M. \& Ritskes-Hoitinga, M. A gold standard publication checklist to improve the quality of animal studies, to fully integrate the three Rs, and to make systematic reviews more feasible. Altern. Lab. Anim. 38, 167-182 (2010).

156. Prinz, F., Schlange, T. \& Asadullah, K. Believe it or not: how much can we rely on published data on potential drug targets? Nat. Rev. Drug Discov. https:// doi.org/10.1038/nrd3439-c1 (2011).

157. Koolhaas, J. M. et al. Stress revisited: a critical evaluation of the stress concept. Neurosci. Biobehav. Rev. https://doi.org/10.1016/..neubiorev.2011.02.003 (2011).

158. American Psychiatric Association. Diagnostic and statistical manual of mental disorders: DSM-III (3rd edn.) (1980).

159. Beery, A. K. \& Zucker, I. Sex bias in neuroscience and biomedical research Neurosci. Biobehav. Rev. https://doi.org/10.1016/j.neubiorev.2010.07.002 (2011).

160. Franconi, F. Brunelleschi, S., Steardo, L. \& Cuomo, V. Gender differences in drug responses. Pharmacol. Res. https://doi.org/10.1016/j.phrs.2006.11.001 (2007).

161. Peters, L., Issakidis, C., Slade, T. \& Andrews, G. Gender differences in the prevalence of DSM-IV and ICD-10 PTSD. Psychol. Med. https://doi.org/10.1017/ S003329170500591X (2006). 
162. Carmassi, C. et al. Gender differences in DSM-5 versus DSM-IV-TR PTSD prevalence and criteria comparison among 512 survivors to the L'Aquila earthquake. J. Affect. Disord. 160, 55-61 (2014).

163. Taylor, S. E. et al. Biobehavioral responses to stress in females: tend-andbefriend, not fight-or-flight. Psychol. Rev. 107, 411-429 (2000).

164. Briscione, M. A., Michopoulos, V., Jovanovic, T. \& Norrholm, S. D. Neuroendocrine underpinnings of increased risk for posttraumatic stress disorder in women. Vitamins Hormones 103, 53-83 (2017).

165. Maeng, L. Y. \& Milad, M. R. Sex differences in anxiety disorders: Interactions between fear, stress, and gonadal hormones. Horm. Behav. https://doi.org/ 10.1016/j.yhbeh.2015.04.002 (2015).

166. Scharfman, H. E. \& Maclusky, N. J. Differential regulation of BDNF, synaptic plasticity and sprouting in the hippocampal mossy fiber pathway of male and female rats. Neuropharmacology https://doi.org/10.1016/j. neuropharm.2013.04.029 (2014)

167. Meziane, H., Ouagazzal, A.-M., Aubert, L., Wietrzych, M. \& Krezel, W. Estrous cycle effects on behavior of C57BL/6J and BALB/CByJ female mice: implications for phenotyping strategies. Genes Brain Behav. 6, 192-200 (2007).

168. Wei, L., David, A., Duman, R. S., Anisman, H. \& Kaffman, A. Early life stress increases anxiety-like behavior in Balbc mice despite a compensatory increase in levels of postnatal maternal care. Horm. Behav. https://doi.org/ 10.1016/j.yhbeh.2010.01.007 (2010).

169. Savignac, H. M., Dinan, T. G. \& Cryan, J. F. Resistance to early-ife stress in mice: effects of genetic background and stress duration. Front. Behav. Neurosci. https://doi.org/10.3389/fnbeh.2011.00013 (2011).

170. Crawley, J. N. et al. Behavioral phenotypes of inbred mouse strains: implications and recommendations for molecular studies. Psychopharmacology https:/doi.org/10.1007/s002130050327 (1997).

171. Cryan, J. F., Markou, A. \& Lucki, I. Assessing antidepressant activity in rodents: recent developments and future needs. Trends in Pharmacol. Sci. https://doi. org/10.1016/S0165-6147(02)02017-5 (2002).

172. Heim, C., Shugart, M., Craighead, W. E. \& Nemeroff, C. B. Neurobiological and psychiatric consequences of child abuse and neglect. Dev. Psychobiol. https:// doi.org/10.1002/dev.20494 (2010).

173. Schmidt, M. V., Wang, X. D. \& Meijer, O. C. Early life stress paradigms in rodents: potential animal models of depression? Psychopharmacology 10.1007/s00213-010-2096-0 (2011).

174. Di Segni, M. et al. Sex-dependent effects of early unstable post-natal environment on response to positive and negative stimuli in adult mice. Neuroscience 413, 1-10 (2019).

175. Spear, L. P. The adolescent brain and age-related behavioral manifestations Neurosci. Biobehav. Rev. https://doi.org/10.1016/S0149-7634(00)00014-2 (2000)

176. McEwen, B. S. Stress, adaptation, and disease: allostasis and allostatic load Ann. NY Acad. Sci. USA https://doi.org/10.1111/j.1749-6632.1998.tb09546.x (1998)

177. Gluckman, P. D., Hanson, M. A. \& Beedle, A. S. Early life events and their consequences for later disease: a life history and evolutionary perspective. Am. J. Hum. Biol. https://doi.org/10.1002/ajhb.20590 (2007).

178. Belsky, J. \& Pluess, M. Beyond diathesis stress: differential susceptibility to environmental influences. Psychol. Bull. https://doi.org/10.1037/a0017376 (2009).

179. Daskalakis, N. P., Bagot, R. C., Parker, K. J., Vinkers, C. H. \& de Kloet, E. R. The three-hit concept of vulnerability and resilience: Toward understanding adaptation to early-life adversity outcome. Psychoneuroendocrinology https:// doi.org/10.1016/j.psyneuen.2013.06.008 (2013).

180. Nederhof, E. \& Schmidt, M. V. Mismatch or cumulative stress: toward an integrated hypothesis of programming effects. Physiol. Behavior https://doi. org/10.1016/j.physbeh.2011.12.008 (2012)

181. Telch, M. J., Rosenfield, D., Lee, H. J. \& Pai, A. Emotional reactivity to a single inhalation of 35\% carbon dioxide and its association with later symptoms of posttraumatic stress disorder and anxiety in soldiers deployed to Iraq. Arch. Gen. Psychiatry https://doi.org/10.1001/archgenpsychiatry.2012.8 (2012).

182. Klengel, T. et al. Allele-specific FKBP5 DNA demethylation mediates genechildhood trauma interactions. Nat. Neurosci. https://doi.org/10.1038/nn.3275 (2013).

183. Van Zuiden, M. et al. Glucocorticoid receptor pathway components predict posttraumatic stress disorder symptom development: a prospective study. Biol. Psychiatry https://doi.org/10.1016/j.biopsych.2011.10.026 (2012).

184. Van Liempt, S., Van Zuiden, M., Westenberg, H., Super, A. \& Vermetten, E. Impact of impaired sleep on the development of PTSD symptoms in combat veterans: a prospective longitudinal cohort study. Depress. Anxiety https://doi. org/10.1002/da.22054 (2013).

185. Gilbertson, M. W. et al. Smaller hippocampal volume predicts pathologic vulnerability to psychological trauma. Nat. Neurosci. https://doi.org/10.1038/ nn958 (2002).

186. Shalev, A. Y. et al. A prospective study of heart rate response following trauma and the subsequent development of posttraumatic stress disorder Arch. Gen. Psychiatry https://doi.org/10.1001/archpsyc.55.6.553 (1998).

187. Pitman, R. K. et al. Biological studies of post-traumatic stress disorder. Nat. Rev. Neurosci. https://doi.org/10.1038/nrn3339 (2012).

188. Yehuda, R. et al. Gene expression patterns associated with posttraumatic stress disorder following exposure to the world trade center attacks. Biol. Psychiatry https://doi.org/10.1016/j.biopsych.2009.02.034 (2009).

189. Strawn, J. R. \& Geracioti, T. D. Noradrenergic dysfunction and the psychopharmacology of posttraumatic stress disorder. Depression Anxiety https://doi. org/10.1002/da.20292 (2008).

190. Karl, A. et al. A meta-analysis of structural brain abnormalities in PTSD. Neurosci. Biobehav. Rev. https://doi.org/10.1016/j.neubiorev.2006.03.004 (2006).

191. Geuze, E. et al. Glucocorticoid receptor number predicts increase in amygdala activity after severe stress. Psychoneuroendocrinology https://oi.org/ 10.1016/j.psyneuen.2012.03.017 (2012).

192. Thomas, D. W. et al. Clinical development success rates 2006-2015. B/O Industry Anal. 1, 16 (2016)

193. Schmidt, U., Kaltwasser, S. F. \& Wotjak, C. T. Biomarkers in posttraumatic stress disorder: overview and implications for future research. Dis. Markers 35, 43-54 (2013).

194. Tufts Center for the Study of Drug Development. CNS Drugs Take 20\% Longer to Develop and to Approve vs. Non-CNS Drugs. Tufts CSDD Impact Report. Vol. 20 (2018).

195. Harrison, R. K. Phase II and phase III failures: 2013-2015. Nat. Rev. Drug Discov. 15, 817 (2016)

196. Arrowsmith, J. Phase III and submission failures: 2007-2010. Nat. Rev. Drug Discov. 10, 87 (2011)

197. Arrowsmith, J. Phase II failures: 2008-2010. Nat. Rev. Drug Discov. 10, 328-329 (2011).

198. Arrowsmith, J. \& Miller, P. Phase II and phase III attrition rates 2011-2012. Nat. Rev. Drug Discov. 12, 569 (2013).

199. Bionomics. BNC210 Update-June 26, 2019. (2019).

200. Morgan, P. et al. Can the flow of medicines be improved? Fundamental pharmacokinetic and pharmacological principles toward improving Phase II survival. Drug Discov. Today 17, 419-424 (2012).

201. Miller, G. Is pharma running out of brainy ideas? Science 329, 502 LP-502504 (2010).

202. O'Brien, P. L., Thomas, C. P., Hodgkin, D., Levit, K. R. \& Mark, T. L. The diminished pipeline for medications to treat mental health and substance use disorders. Psychiatr. Serv. 65, 1433-1438 (2014).

203. Bionomics. BNC210 Phase 2 PTSD Clinical Trial Results Presentation. (2018).

204. U.S. Department of Health and Human Services-Food and Drug Administration. Innovation/Stagnation: Challenge and Opportunity on the Critical Path to New Medical Products. (2004).

205. Morris, S. E. \& Cuthbert, B. N. Research domain criteria: cognitive systems, neural circuits, and dimensions of behavior. Dialogues Clin. Neurosci. https:// doi.org/10.1097/ALN.0b013e318212ba87 (2012).

206. Schmidt, U. \& Vermetten, E. Integrating NIMH research domain criteria (RDoC) into PTSD research. Curr. Topics Behav. Neurosci. 69-91 (2017).

207. Kunimatsu, A., Yasaka, K., Akai, H., Kunimatsu, N. \& Abe, O. MRI findings in posttraumatic stress disorder. J. Magn. Reson. Imaging https://doi.org/ 10.1002/jmri.26929 (2019)

208. Zhang, N. et al. Mapping resting-state brain networks in conscious animals. J. Neurosci. Methods https://doi.org/10.1016/j.jneumeth.2010.04.001 (2010).

209. Dopfel, D. \& Zhang, N. Mapping stress networks using functional magnetic resonance imaging in awake animals. Neurobiol. Stress https://doi.org/ 10.1016/j.ynstr.2018.06.002 (2018).

210. Yizhar, O., Fenno, L. E., Davidson, T. J., Mogri, M. \& Deisseroth, K. Optogenetics in neural systems. Neuron https://doi.org/10.1016/j.neuron.2011.06.004 (2011).

211. Campbell, E. J. \& Marchant, N. J. The use of chemogenetics in behavioura neuroscience: receptor variants, targeting approaches and caveats. $\mathrm{Br}$. J. Pharmacol. 175, 994-1003 (2018).

212. Lee, J. H. et al. Global and local fMRI signals driven by neurons defined optogenetically by type and wiring. Nature https://doi.org/10.1038/ nature09108 (2010) 
213. Giorgi, A. et al. Brain-wide mapping of endogenous serotonergic transmission via chemogenetic fMRI. Cell Rep. 21, 910-918 (2017).

214. Ferenczi, E. A. et al. Prefrontal cortical regulation of brainwide circuit dynamics and reward-related behavior. Science 351, aac9698-aac9698 (2016).

215. Liu, X., Yuan, J., Guang, Y., Wang, X. \& Feng, Z. Longitudinal in vivo diffusion tensor imaging detects differential microstructural alterations in the hippocampus of chronic social defeat stress-susceptible and resilient mice. Front. Neurosci. 12, 613 (2018).

216. Uhlhaas, P. J. et al. Magnetoencephalography as a tool in psychiatric research: current status and perspective. Biol. Psychiatry Cogn. Neurosci. Neuroimaging 2, 235-244 (2017).

217. Liang, Z., Ma, Y., Watson, G. D. R. \& Zhang, N. Simultaneous GCaMP6based fiber photometry and fMRI in rats. J. Neurosci. Methods $\mathbf{2 8 9}$ 31-38 (2017).

218. Schlegel, F. et al. Fiber-optic implant for simultaneous fluorescencebased calcium recordings and BOLD fMRI in mice. Nat. Protoc. 13, 840-855 (2018).

219. Meyer, J. S. \& Hamel, A. F. Models of stress in nonhuman primates and their relevance for human psychopathology and endocrine dysfunction. ILAR J. $\mathbf{5 5}$, 347-360 (2014).

220. Coleman, K. \& Pierre, P. J. Assessing anxiety in nonhuman primates. ILAR J. 55 333-346 (2014).

221. Miles, O. W. \& Maren, S. Role of the bed nucleus of the stria terminalis in PTSD: insights from preclinical models. Front. Behav. Neurosci. 13, 68 (2019).

222. Jennings, J. H. et al. Distinct extended amygdala circuits for divergent motivational states. Nature 496, 224-228 (2013).

223. Fox, A. S. et al. Functional connectivity within the primate extended amygdala is heritable and associated with early-life anxious temperament. J. Neurosci. 38, 7611 LP-7617621 (2018).

224. Mikics, E., Baranyi, J. \& Haller, J. Rats exposed to traumatic stress bury unfamiliar objects-A novel measure of hyper-vigilance in PTSD models? Physiol. Behav. 94, 341-348 (2008).

225. Walf, A. A. \& Frye, C. A. The use of the elevated plus maze as an assay of anxiety-related behavior in rodents. Nat. Protoc. https://doi.org/10.1038/ nprot.2007.44 (2007).

226. Graeff, F. G., Ferreira Netto, C. \& Zangrossi, H. The elevated T-maze as an experimental model of anxiety. Neurosci. Biobehav. Rev. https://doi.org/ 10.1016/S0149-7634(98)00024-4 (1998).

227. Shepherd, J. K., Grewal, S. S., Fletcher, A., Bill, D. J. \& Dourish, C. T. Behavioural and pharmacological characterisation of the elevated 'zero-maze' as an animal model of anxiety. Psychopharmacology https:/doi.org/10.1007/ BF02244871 (1994).

228. Bourin, M. \& Hascoët, M. The mouse light/dark box test. Eur. J. Pharmacol. 463, 55-65 (2003).

229. Arrant, A. E., Schramm-Sapyta, N. L. \& Kuhn, C. M. Use of the light/dark test for anxiety in adult and adolescent male rats. Behav. Brain Res. 256, 119-127 (2013).

230. Gould, T. D., Dao, D. T. \& Kovacsics, C. E. The Open Field Test BT-Mood and Anxiety Related Phenotypes in Mice: Characterization Using Behavioral Tests (ed. Gould, T. D.) 1-20 (Humana Press, 2009).

231. Bodnoff, S. R., Suranyi-Cadotte, B., Aitken, D. H., Quirion, R. \& Meaney, M. J. The effects of chronic antidepressant treatment in an animal model of anxiety. Psychopharmacology. https://doi.org/10.1007/BF00181937 (1988).

232. Ohl, F., Holsboer, F. \& Landgraf, R. The modified hole board as a differential screen for behavior in rodents. Behav. Res. Methods Instruments Comput. https:/doi.org/10.3758/BF03195393 (2001).

233. Nachman, M. \& Ashe, J. H. Learned taste aversions in rats as a function of dosage, concentration, and route of administration of LiCl. Physiol. Behav. https://doi.org/10.1016/0031-9384(73)90089-9 (1973).

234. Philbert, J. et al. Acute inescapable stress exposure induces long-term sleep disturbances and avoidance behavior: a mouse model of post-traumatic stress disorder (PTSD). Behav. Brain Res. 221, 149-154 (2011).

235. Pamplona, F. A. et al. Prolonged fear incubation leads to generalized avoidance behavior in mice. J. Psychiatr. Res. 45, 354-360 (2011).

236. Cosentino, L. et al. Methyl-CpG binding protein 2 functional alterations provide vulnerability to develop behavioral and molecular features of posttraumatic stress disorder in male mice. Neuropharmacology 160, 107664 (2019).

237. Patin, V., Lordi, B., Vincent, A. \& Caston, J. Effects of prenatal stress on anxiety and social interactions in adult rats. Dev. Brain Res. https:/doi.org/10.1016/j. devbrainres.2005.09.010 (2005).
238. Vorhees, C. V. \& Williams, M. T. Morris water maze: procedures for assessing spatial and related forms of learning and memory. Nat. Protoc. 1, 848-858 (2006).

239. Diamond, D. M., Park, C. R., Heman, K. L. \& Rose, G. M. Exposing rats to a predator impairs spatial working memory in the radial arm water maze. Hippocampus 9, 542-552 (1999).

240. Deacon, R. M. J. \& Rawlins, J. N. P. T-maze alternation in the rodent. Nat. Protoc. https://doi.org/10.1038/nprot.2006.2 (2006).

241. Antunes, M. and Biala, G. The novel object recognition memory: neurobiology, test procedure, and its modifications. Cogn. Process. https://doi.org/ 10.1007/s10339-011-0430-z (2012).

242. Muhie, S. et al. Molecular indicators of stress-induced neuroinflammation in a mouse model simulating features of post-traumatic stress disorder. Transl. Psychiatry 7, e1135 (2017).

243. Dellu, F., Mayo, W., Cherkaoui, J., Le Moal, M. \& Simon, H. A two-trial memory task with automated recording: study in young and aged rats. Brain Res. https:/doi.org/10.1016/0006-8993(92)91352-F (1992).

244. Barnes, C. A. Memory deficits associated with senescence: a neurophysiological and behavioral study in the rat. J. Comp. Physiol. Psychol. https://doi.org/ 10.1037/h0077579 (1979)

245. Rosenfeld, C. S. \& Ferguson, S. A. Barnes maze testing strategies with small and large rodent models. J. Vis. Exp. https://doi.org/10.3791/51194 (2014).

246. Phillips, R. G. \& LeDoux, J. E. Differential contribution of amygdala and hippocampus to cued and contextual fear conditioning. Behav. Neurosci. https:// doi.org/10.1037/0735-7044.106.2.274 (1992).

247. Curzon, P., Rustay, N. R. \& Browman, K. E. Cued and contextual fear conditioning for rodents. Methods Behav. Anal. Neurosci. 115, 19-37 (2009).

248. Cohen, H., Liberzon, I. \& Richter-Levin, G. Exposure to extreme stress impairs contextual odour discrimination in an animal model of PTSD. Int. J. Neuropsychopharmacol. 12, 291-303 (2009).

249. Ögren, S. O. \& Stiedl, O. Passive avoidance. in Encyclopedia of Psychopharmacology (ed. Stolerman, I. P.) 960-967 (Springer Berlin Heidelberg, 2010),

250. Der-Avakian, A., D'Souza, M. S., Pizzagalli, D. A. \& Markou, A. Assessment of reward responsiveness in the response bias probabilistic reward task in rats: implications for cross-species translational research. Transl. Psychiatry https:/ doi.org/10.1038/tp.2013.74 (2013).

251. Porsolt, R. D., Le Pichon, M. \& Jalfre, M. Depression: a new animal model sensitive to antidepressant treatments. Nature 266, 730-732 (1977).

252. Slattery, D. A. \& Cryan, J. F. Using the rat forced swim test to assess antidepressant-like activity in rodents. Nat. Protoc. 7, 1009 (2012).

253. Steru, L., Chermat, R., Thierry, B. \& Simon, P. The tail suspension test: a new method for screening antidepressants in mice. Psychopharmacology (Berl). https://doi.org/10.1007/BF00428203 (1985).

254. Katz, R. J., Roth, K. A. \& Carroll, B. J. Acute and chronic stress effects on open field activity in the rat: implications for a model of depression. Neurosci. Biobehav. Rev. https://doi.org/10.1016/0149-7634(81)90005-1 (1981).

255. Espejo, E. F. \& Mir, D. Structure of the rat's behaviour in the hot plate test. Behav. Brain Res. https://doi.org/10.1016/0166-4328(93)90035-O (1993).

256. Eddy, N. B. \& Leimbach, D. Synthetic analgesics. II. Dithienylbutenyl- and dithienylbutylamines. J. Pharmacol. Exp. Ther. 107, 385-393 (1953).

257. Hole, K. \& Tjølsen, A. Tail flick test. In Encyclopedia of Pain (eds. Schmidt, R. F. \& Willis, W. D.) 2392-2395 (Springer Berlin Heidelberg, 2007).

258. Chaplan, S. R., Bach, F. W., Pogrel, J. W., Chung, J. M. \& Yaksh, T. L. Quantitative assessment of tactile allodynia in the rat paw. J. Neurosci. Methods https:/doi. org/10.1016/0165-0270(94)90144-9 (1994).

259. Willner, P., Towell, A., Sampson, D., Sophokleous, S. \& Muscat, R. Reduction of sucrose preference by chronic unpredictable mild stress, and its restoration by a tricyclic antidepressant. Psychopharmacology https://doi.org/10.1007/ BF00187257 (1987)

260. Carlezon, W. A. Jr \& Chartoff, E. H. Intracranial self-stimulation (ICSS) in rodents to study the neurobiology of motivation. Nat. Protoc. 2, 2987 (2007).

261. Markou, A. \& Koob, G. F. Construct validity of a self-stimulation threshold paradigm: effects of reward and performance manipulations. Physiol. Behav. https:/doi.org/10.1016/0031-9384(92)90211-J (1992).

262. File, S. E. \& Seth, P. A review of 25 years of the social interaction test. Eur. J. Pharmacol. 463, 35-53 (2003).

263. Lukas, M. et al. The neuropeptide oxytocin facilitates pro-social behavior and prevents social avoidance in rats and mice. Neuropsychopharmacology $\mathbf{3 6}$, 2159-2168 (2011).

264. Berton, O. et al. Essential role of BDNF in the mesolimbic dopamine pathway in social defeat stress. Science. 311, 864-868 (2006). 
265. Avitsur, R., Cohen, E. \& Yirmiya, R. Effects of interleukin-1 on sexual attractivity in a model of sickness behavior. Physiol. Behav. https://doi.org/10.1016/S00319384(97)00381-8 (1997).

266. Haller, J. \& Bakos, N. Stress-induced social avoidance: a new model of stressinduced anxiety? Physiol. Behav. https://doi.org/10.1016/S0031-9384(02) 00860-0 (2002)

267. Nadler, J. J. et al. Automated apparatus for quantitation of social approach behaviors in mice. Genes, Brain Behav. 3, 303-314 (2004).

268. Yang, M. \& Crawley, J. N. Simple behavioral assessment of mouse olfaction. Curr. Protoc. Neurosci. 8, Unit-8.24 (2009)

269. Deacon, R. M. J. Digging and marble burying in mice: simple methods for in vivo identification of biological impacts. Nat. Protoc. 1, 122 (2006).

270. Pilz, P. K. D. \& Schnitzler, H.-U. Habituation and sensitization of the acoustic startle response in rats: amplitude, threshold, and latency measures. Neurobiol. Learn. Mem. 66, 67-79 (1996).

271. Valsamis, B. \& Schmid, S. Habituation and prepulse inhibition of acoustic startle in rodents. J. Vis. Exp. https://doi.org/10.3791/3446 (2011).

272. Brady, A. M. \& Floresco, S. B. Operant procedures for assessing behavioral flexibility in rats. J. Vis. Exp. 96, e52387-e52387 (2015).

273. Piao, C. et al. Altered function in medial prefrontal cortex and nucleus accumbens links to stress-induced behavioral inflexibility. Behav. Brain Res. https://doi.org/10.1016/j.bbr.2016.09.017 (2017).

274. Kavushansky, A., Ben-Shachar, D., Richter-Levin, G. \& Klein, E. Physical stress differs from psychosocial stress in the pattern and time-course of behavioral responses, serum corticosterone and expression of plasticity-related genes in the rat. Stress 12, 412-425 (2009).

275. Diehl, L. A. et al. Long-lasting effects of maternal separation on an animal model of post-traumatic stress disorder: effects on memory and hippocampal oxidative stress. Neurochem. Res. 37, 700-707 (2012).

276. Louvart, $\mathrm{H}$. et al. Effects of a single footshock followed by situational reminders on HPA axis and behaviour in the aversive context in male and female rats. Psychoneuroendocrinology 31, 92-99 (2006).

277. Machawal, L. \& Kumar, A. Possible involvement of nitric oxide mechanism in the neuroprotective effect of rutin against immobilization stress induced anxiety like behaviour, oxidative damage in mice. Pharmacol. Reports https:// doi.org/10.1016/j.pharep.2013.08.001 (2014).

278. Samad, N., Saleem, A., Yasmin, F. \& Shehzad, M. A. Quercetin protects against stress-induced anxiety- and depression-like behavior and improves memory in male mice. Physiol. Res. (2018).

279. Armario, A., Gil, M., Marti, J., Pol, O. \& Balasch, J. Influence of various acute stressors on the activity of adult male rats in a holeboard and in the forced swim test. Pharmacol. Biochem. Behav. https://doi.org/10.1016/0091-3057(91) 90194-7 (1991)

280. Andero, R. et al. Effect of 7,8-dihydroxyflavone, a small-molecule TrkB agonist, on emotional learning. Am. J. Psychiatry 168, 163-172 (2011).

281. Kim, J. W. et al. Social support rescues acute stress-induced cognitive impairments by modulating ERK1/2 phosphorylation in adolescent mice. Sci. Rep. https://doi.org/10.1038/s41598-018-30524-4 (2018).

282. Pastor-Ciurana, J. et al. Prior exposure to repeated immobilization or chronic unpredictable stress protects from some negative sequels of an acute immobilization. Behav. Brain Res. https://doi.org/10.1016/j.bbr.2014.02.028 (2014).

283. Fuentes, S., Carrasco, J., Armario, A. \& Nadal, R. Behavioral and neuroendocrine consequences of juvenile stress combined with adult immobilization in male rats. Horm. Behav. 66, 475-486 (2014).

284. Adamec, R., Toth, M., Haller, J., Halasz, J. \& Blundell, J. A comparison of activation patterns of cells in selected prefrontal cortical and amygdala areas of rats which are more or less anxious in response to predator exposure or submersion stress. Physiol. Behav. https://doi.org/10.1016/j.physbeh.2011. 09.016 (2012).

285. Ardi, Z., Ritov, G., Lucas, M. \& Richter-Levin, G. The effects of a reminder of underwater trauma on behaviour and memory-related mechanisms in the rat dentate gyrus. Int. J. Neuropsychopharmacol. 17, 571-580 (2014).

286. Toledano, D. \& Gisquet-Verrier, P. Only susceptible rats exposed to a model of PTSD exhibit reactivity to trauma-related cues and other symptoms: An effect abolished by a single amphetamine injection. Behav. Brain Res. 272, 165-174 (2014).

287. Lin, C.-C., Tung, C.-S. \& Liu, Y.-P. Escitalopram reversed the traumatic stressinduced depressed and anxiety-like symptoms but not the deficits of fear memory. Psychopharmacology 233, 1135-1146 (2016).
288. Brand, L., Groenewald, I., Stein, D. J., Wegener, G. \& Harvey, B. H. Stress and restress increases conditioned taste aversion learning in rats: Possible frontal cortical and hippocampal muscarinic receptor involvement. Eur. J. Pharmacol. 586, 205-211 (2008).

289. Tanaka, K.-I., Yagi, T., Nanba, T. \& Asanuma, M. Application of single prolonged stress induces post-traumatic stress disorder-like characteristics in mice. Acta Med. Okayama 72, 479-485 (2018).

290. Han, F., Ding, J. \& Shi, Y. Expression of amygdala mineralocorticoid receptor and glucocorticoid receptor in the single-prolonged stress rats. BMC NeurosCi. https://doi.org/10.1186/1471-2202-15-77 (2014).

291. George, S. A. et al. Alterations in cognitive flexibility in a rat model of posttraumatic stress disorder. Behav. Brain Res. https://doi.org/10.1016/j. bbr.2015.02.051 (2015)

292. Eagle, A. L., Fitzpatrick, C. J. \& Perrine, S. A. Single prolonged stress impairs social and object novelty recognition in rats. Behav. Brain Res. https://doi.org/ 10.1016/j.bbr.2013.09.014 (2013).

293. Wu, Z. et al. Behavioral changes over time in post-traumatic stress disorder: insights from a rat model of single prolonged stress. Behav. Processes https:// doi.org/10.1016/j.beproc.2016.01.001 (2016).

294. Zhang, Y., Schalo, I., Durand, C. \& Standifer, K. M. Sex differences in nociceptin/orphanin FQ peptide receptor-mediated pain and anxiety symptoms in a preclinical model of post-traumatic stress disorder. Front. Psychiatry $\mathbf{9}, 731$ (2019).

295. Noble, L. J. et al. Effects of vagus nerve stimulation on extinction of conditioned fear and post-traumatic stress disorder symptoms in rats. Transl. Psychiatry https://doi.org/10.1038/tp.2017.191 (2017).

296. Khan, S. \& Liberzon, I. Topiramate attenuates exaggerated acoustic startle in an animal model of PTSD. Psychopharmacology. https://doi.org/10.1007/ s00213-003-1634-4 (2004).

297. Vanderheyden, W. M. et al. Sleep alterations following exposure to stress predict fear-associated memory impairments in a rodent model of PTSD. Exp. Brain Res. https://doi.org/10.1007/s00221-015-4302-0 (2015).

298. Moshfegh, C. M., Elkhatib, S. K., Collins, C. W., Kohl, A. J. \& Case, A. J. Autonomic and redox imbalance correlates with T-lymphocyte inflammation in a model of chronic social defeat stress. Front. Behav. Neurosci. https://doi.org/ 10.3389/fnbeh.2019.00103 (2019).

299. Wang, X. D. et al. Forebrain CRHR1 deficiency attenuates chronic stressinduced cognitive deficits and dendritic remodeling. Neurobiol. Dis. 42, 300-310 (2011).

300. Patki, G., Solanki, N., Atrooz, F., Allam, F. \& Salim, S. Depression, anxiety-like behavior and memory impairment are associated with increased oxidative stress and inflammation in a rat model of social stress. Brain Res. 1539, 73-86 (2013).

301. Narayanan, V. et al. Social defeat: Impact on fear extinction and Amygdalaprefrontal cortical theta synchrony in 5-HTT deficient mice. PLoS One $\mathbf{6}$ https://doi.org/10.1371/journal.pone.0022600 (2011).

302. Der-Avakian, A. et al. Social defeat disrupts reward learning and potentiates striatal nociceptin/orphanin FQ mRNA in rats. Psychopharmacol. (Berl.). 234, 1603-1614 (2017).

303. Monleón, S., Duque, A. \& Vinader-Caerols, C. Inhibitory avoidance learning in CD1 mice: effects of chronic social defeat stress. Behav. Process. 115, 64-69 (2015).

304. Yu, T. et al. Cognitive and neural correlates of depression-like behaviour in socially defeated mice: an animal model of depression with cognitive dysfunction. Int. J. Neuropsychopharmacol. 14, 303-317 (2011).

305. Laredo, S. A. et al. Effects of defeat stress on behavioral flexibility in males and females: modulation by the mu-opioid receptor. Eur. J. Neurosci. https://doi. org/10.1111/ejn.12824 (2015).

306. Jianhua, F., Wei, W., Xiaomei, L. \& Shao-Hui, W. Chronic social defeat stress leads to changes of behaviour and memory-associated proteins of young mice. Behav. Brain Res. https://doi.org/10.1016/j.bbr.2016.09.011 (2017).

307. Rygula, R. et al. Anhedonia and motivational deficits in rats: Impact of chronic social stress. Behav. Brain Res. 162, 127-134 (2005).

308. Der-Avakian, A., Mazei-Robison, M. S., Kesby, J. P., Nestler, E. J. \& Markou, A Enduring deficits in brain reward function after chronic social defeat in rats: Susceptibility, resilience, and antidepressant response. Biol. Psychiatry 76 542-549 (2014).

309. Bharwani, A., Mian, M. F., Surette, M. G., Bienenstock, J. \& Forsythe, P. Oral treatment with Lactobacillus rhamnosus attenuates behavioural deficits and immune changes in chronic social stress. BMC Med. https://doi.org/10.1186/ s12916-016-0771-7 (2017). 
310. Trainor, B. C. et al. Sex differences in social interaction behavior following social defeat stress in the monogamous California mouse (peromyscus californicus). PLOS ONE https://doi.org/10.1371/journal. pone.0017405 (2011).

311. Pulliam, J. V. K., Dawaghreh, A. M., Alema-Mensah, E. \& Plotsky, P. M. Social defeat stress produces prolonged alterations in acoustic startle and body weight gain in male Long Evans rats. J. Psychiatr. Res. 44, 106-111 (2010).

312. Wells, A. M. et al. Effects of chronic social defeat stress on sleep and circadian rhythms are mitigated by Kappa-Opioid receptor antagonism. J. Neurosci. 37, 7656-7668 (2017).

313. Patki, G., Solanki, N. \& Salim, S. Witnessing traumatic events causes severe behavioral impairments in rats. Int. J. Neuropsychopharmacol. 17, 2017-2029 (2014).

314. Li, M., Xu, H. \& Wang, W. An improved model of physical and emotional social defeat: different effects on social behavior and body weight of adolescent mice by interaction with social support. Front. Psychiatry 9, 688 (2018).

315. Patki, G., Salvi, A., Liu, H. \& Salim, S. Witnessing traumatic events and posttraumatic stress disorder: insights from an animal model. Neurosci. Lett. 600, 28-32 (2015)

316. Gautam, A. et al. Acute and chronic plasma metabolomic and liver transcriptomic stress effects in a mouse model with features of post-traumatic stress disorder. PLOS ONE 10, https://doi.org/10.1371/journal.pone.0117092 (2015).

317. Bian, Y. et al. Identification of key genes and pathways in post-traumatic stress disorder using microarray analysis. Front. Psychol. 10, 302 (2019).

318. Bulos, E. M., Pobbe, R. L. H. \& Zangrossi, H. Behavioral consequences of predator stress in the rat elevated T-maze. Physiol. Behav. https:/doi.org/ 10.1016/j.physbeh.2015.04.019 (2015).

319. Sharma, R., Sahota, P. \& Thakkar, M. M. Severe and protracted sleep disruptions in mouse model of post-traumatic stress disorder. Sleep 1-12 (2018)

320. Wu, Y. P. et al. Predator stress-induced depression is associated with inhibition of hippocampal neurogenesis in adult male mice. Neural Regen. Res. https://doi.org/10.4103/1673-5374.244792 (2019).

321. Shallcross, J. et al. The divergent effects of CDPPB and Cannabidiol on fear extinction and anxiety in a predator scent stress model of PTSD in rats. Front. Behav. Neurosci. https://doi.org/10.3389/fnbeh.2019.00091 (2019).

322. Banik, A. \& Anand, A. Loss of learning in mice when exposed to rat odor: a water maze study. Behav. Brain Res. 216, 466-471 (2011).

323. Louvart, H., Maccari, S., Ducrocq, F., Thomas, P. \& Darnaudéry, M. Long-term behavioural alterations in female rats after a single intense footshock followed by situational reminders. Psychoneuroendocrinology 30, 316-324 (2005).

324. Nahvi, R. J., Nwokafor, C., Serova, L. I. \& Sabban, E. L. Single prolonged stress as a prospective model for posttraumatic stress disorder in females. Front. Behav. Neurosci. 13, 17 (2019).

325. Shimamoto, A., Holly, E. N., Boyson, C. O., Debold, J. F. \& Miczek, K. A. Individual differences in anhedonic and accumbal dopamine responses to chronic social stress and their link to cocaine self-administration in female rats. Psychopharmacology. https://doi.org/10.1007/s00213-014-3725-9 (2015).

326. Bourke, C. H. \& Neigh, G. N. Exposure to repeated maternal aggression induces depressive-like behavior and increases startle in adult female rats. Behav. Brain Res. https://doi.org/10.1016/j.bbr.2011.11.001 (2012).

327. Finnell, J. E. et al. Essential role of ovarian hormones in susceptibility to the consequences of witnessing social defeat in female rats. Biol. Psychiatry https://doi.org/10.1016/j.biopsych.2018.01.013 (2018).

328. Iñiguez, S. D. et al. Vicarious social defeat stress induces depression-related outcomes in female mice. Biol. Psychiatry 83, 9-17 (2018).

329. Burke, H. M. et al. Sex-specific impairment of spatial memory in rats following a reminder of predator stress. Stress https://doi.org/10.3109/10253890. 2013.791276 (2013)
330. Park, C. R., Zoladz, P. R., Conrad, C. D., Fleshner, M. \& Diamond, D. M. Acute predator stress impairs the consolidation and retrieval of hippocampusdependent memory in male and female rats. Learn. Mem. https://doi.org/ 10.1101/Im.721108 (2008)

331. Daskalakis, N. P., Cohen, H., Cai, G., Buxbaum, J. D. \& Yehuda, R. Expression profiling associates blood and brain glucocorticoid receptor signaling with trauma-related individual differences in both sexes. Proc. Natl Acad. Sci. USA https://doi.org/10.1073/pnas.1401660111 (2014).

332. Sawamura, T. et al. Effect of paroxetine on a model of posttraumatic stress disorder in rats. Neurosci. Lett. https://doi.org/10.1016/j.neulet.2003.12.039 (2004).

333. Zhang, L.-M. et al. Anxiolytic effects of ketamine in animal models of posttraumatic stress disorder. Psychopharmacoloy 232, 663-672 (2015).

334. Kumar, A., Garg, R., Gaur, V. \& Kumar, P. Nitric oxide mechanism in protective effect of imipramine and venlafaxine against acute immobilization stressinduced behavioral and biochemical alteration in mice. Neurosci. Lett. 467, 72-75 (2009).

335. Takahashi, T., Morinobu, S., Iwamoto, Y. \& Yamawaki, S. Effect of paroxetine on enhanced contextual fear induced by single prolonged stress in rats. Psychopharmacology 189, 165-173 (2006)

336. Perrine, S. A. et al. Severe, multimodal stress exposure induces PTSD-like characteristics in a mouse model of single prolonged stress. Behav. Brain Res. 303, 228-237 (2016)

337. Guo, L. et al. GHS-R1a deficiency alleviates depression-related behaviors after chronic social defeat stress. Front. Neurosci. 13, 364 (2019).

338. Yang, R. et al. Core modular blood and brain biomarkers in social defeat mouse model for post traumatic stress disorder. BMC Syst. Biol. 7, https://doi. org/10.1186/1752-0509-7-80 (2013).

339. Diamond, D. M. et al. Influence of predator stress on the consolidation versus retrieval of long-term spatial memory and hippocampal spinogenesis. Hippocampus $16,571-576$ (2006).

340. Belzung, C., El Hage, W., Moindrot, N. \& Griebel, G. Behavioral and neurochemical changes following predatory stress in mice. Neuropharmacology $\mathbf{4 1}$, 400-408 (2001).

341. Wilson, C. B. et al. Differential effects of sertraline in a predator exposure animal model of post-traumatic stress disorder. Front. Behav. Neurosci. 8, 10.3389/fnbeh.2014.00256 (2014).

342. Matar, M. A., Cohen, H., Kaplan, Z. \& Zohar, J. The effect of early poststressor intervention with sertraline on behavioral responses in an animal model of post-traumatic stress disorder. Neuropsychopharmacology 31, 2610-2618 (2006).

343. Belda, X., Fuentes, S., Nadal, R. \& Armario, A. A single exposure to immobilization causes long-lasting pituitary-adrenal and behavioral sensitization to mild stressors. Horm. Behav. 54, 654-661 (2008).

344. Martí, O., García, A., Vellès, A., Harbuz, M. S. \& Armario, A. Evidence that a single exposure to aversive stimuli triggers long-lasting effects in the hypothalamus-pituitary-adrenal axis that consolidate with time. Eur. J. Neurosci. 13, 129-136 (2001).

345. Sood, R. et al. Underwater trauma causes a long-term specific increase in the expression of cyclooxygenase- 2 in the ventral CA1 of the hippocampus. Psychoneuroendocrinology 49, 62-68 (2014).

346. Monleón, S., Duque, A. \& Vinader-Caerols, C. Effects of several degrees of chronic social defeat stress on emotional and spatial memory in CD1 mice. Behav. Proces. https://doi.org/10.1016/j.beproc.2015.12.002 (2016).

347. Adamec, R. E., Burton, P., Shallow, T. \& Budgell, J. NMDA receptors mediate lasting increases in anxiety-like behavior produced by the stress of predator exposure-implications for anxiety associated with posttraumatic stress disorder. Physiol. Behav. 65, 723-737 (1998).

348. Kozlovsky, N. et al. Long-term down-regulation of BDNF mRNA in rat hippocampal CA1 subregion correlates with PTSD-like behavioural stress response. Int. J. Neuropsychopharmacol. 10, 741-758 (2007). 